\title{
Combination of Mesoscale and Synoptic Mechanisms for Triggering an Isolated Thunderstorm: Observational Case Study of CSIP IOP 1
}

\author{
Cyril Morcrette, ${ }^{*}$ Humphrey Lean, ${ }^{+}$Keith Browning, ${ }^{*}$ John Nicol, ${ }^{*}$ Nigel Roberts, ${ }^{+}$ \\ Peter Clark, ${ }^{+}$Andrew Russell, ${ }^{\#}$ And Alan Blyth ${ }^{\circledR}$ \\ * Department of Meteorology, University of Reading, Reading, United Kingdom \\ + JCMM, Met Office, University of Reading, Reading, United Kingdom \\ \# School of Earth, Atmospheric, and Environmental Sciences, University of Manchester, Manchester, United Kingdom \\ @ School of Earth and Environment, University of Leeds, Leeds, United Kingdom
}

(Manuscript received 27 October 2006, in final form 12 January 2007)

\begin{abstract}
An isolated thunderstorm formed in the southern United Kingdom on 15 June 2005 and moved through the area where a large number of observational instruments were deployed as part of the Convective Storm Initiation Project. Earlier, a convergence line had formed downstream of Devon in the southwest of the United Kingdom in a southwesterly airflow, along which a series of light showers had formed. The depth of these showers was limited by a capping inversion, or lid, at around $2.5 \mathrm{~km}$. The deep thunderstorm convection developed from one of these showers when the convection broke through the lid and ascended up to the next inversion, associated with a tropopause fold at around $6 \mathrm{~km}$. A series of clear-air reflectivity RHIs are used to map the height of the capping inversion and its lifting resulting from the ascent along the convergence line. The origins of the lid are tracked back to some descent from the midtroposphere along dry adiabats. The strength of the lid was weaker along a northwest-to-southeast-oriented region located behind an overrunning upper cold front. The transition from shallow to deep convection occurred where this region with a weaker lid intersected the region with a raised lid, oriented southwest to northeast, downstream of Devon. A very high resolution forecast model that is being developed by the Met Office predicted the isolated thunderstorm successfully. This success depended on the accurate representation of the following two scales: the synoptic-scale and the surface-forced mesoscale convergence line. The interaction between these scales localized the convection sufficiently in space and time for the initiation and subsequent development to be highly predictable despite the relatively poor representation in the model of processes at the cloud scale.
\end{abstract}

\section{Introduction}

Advance knowledge of the location of precipitation is the main factor limiting the accuracy of forecasts of river flow (Collier 1996). Flash flooding, which can cause severe disruption and damage to property, is often due to heavy or localized convective precipitation, for example, the flooding in Boscastle, United Kingdom, on 16 August 2004 (Burt 2005; Golding et al. 2005). Consequently, it is important to be able to forecast the timing and location of convective precipitation. This can be achieved only if the mechanisms leading to the initiation of convection at a particular time and

Corresponding author address: Dr. C. J. Morcrette, Met Office, FitzRoy Road, Exeter EX1 3PB, United Kingdom.

E-mail: cyril.morcrette@metoffice.gov.uk place are accurately represented in the forecast model. Further improvements to model performance will require a better understanding of these mechanisms. Up until now, only a small amount of research has been undertaken in the United Kingdom to observe the atmosphere during the initiation of precipitating convection (Bennett et al. 2006).

The Convective Storm Initiation Project (CSIP) was organized to obtain detailed observations of the state of the atmosphere prior to, and during, the early stages of the development of precipitating convection. The field campaign associated with CSIP was carried out in June, July, and August 2005, following a pilot campaign in July 2004. Browning et al. (2006) summarize the 18 intensive observation periods (IOPs) and show the locations of the numerous observational instruments deployed in southern United Kingdom during the cam- 


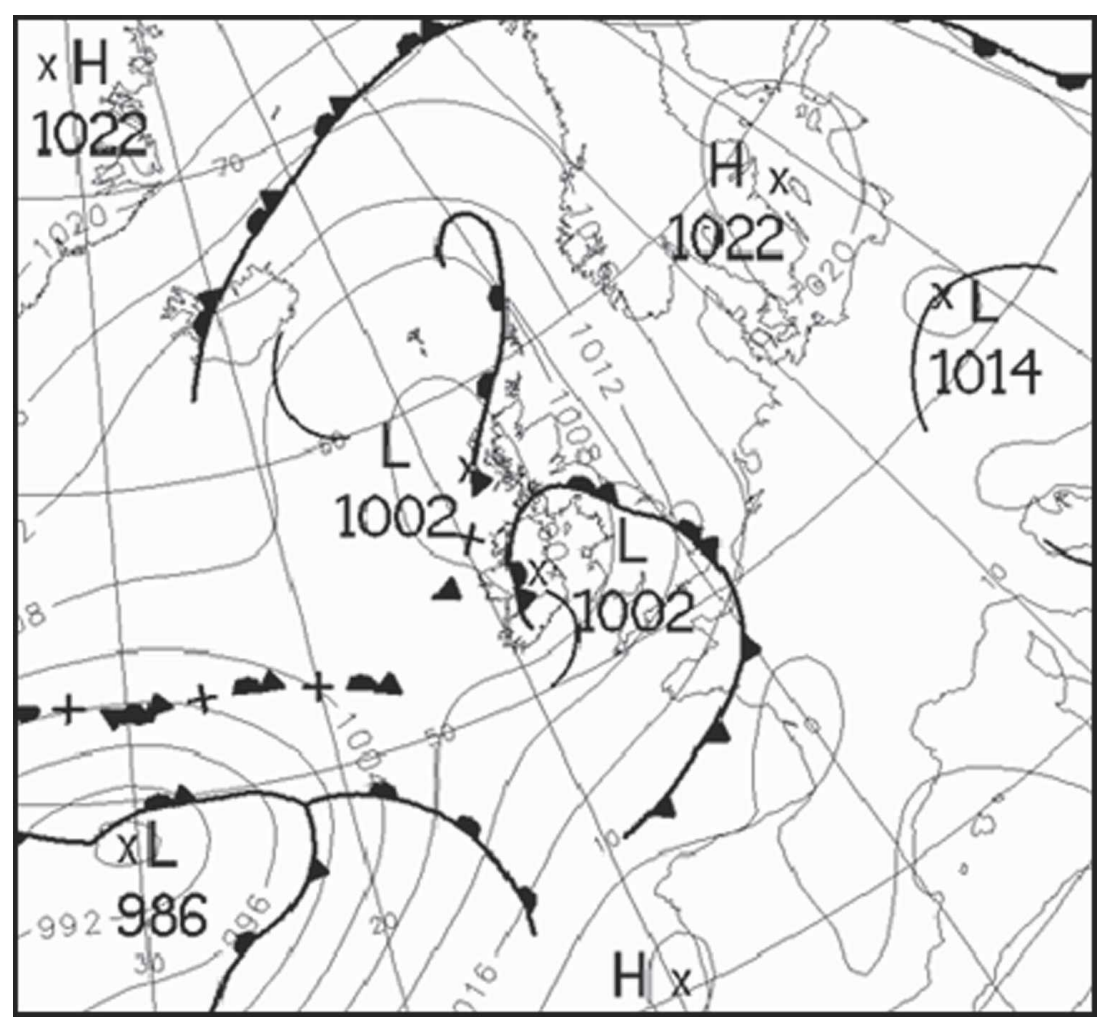

FIG. 1. Operational analysis for 1200 UTC on 15 Jun 2005.

paign. By studying these IOPs we shall improve our understanding of the mechanisms that are important in the initiation of convection in an extratropical maritime environment, such as the United Kingdom. A comparison with simulations from a very high resolution numerical weather prediction (NWP) model will allow the successes and failures of the model to be assessed. This assessment, together with the improved understanding, will then lead to informed suggestions for model improvement. It is hoped that once the abilities of the NWP model to forecast the initiation and development of precipitating convection have been proven, it will be possible to use it as part of a new nowcasting system (Golding 2005).

This paper presents an observational case study of an isolated thunderstorm that formed over southern United Kingdom during IOP 1. Key observing systems used in this study were serial rawindondes, released from several of the special CSIP sites, and the 1275$\mathrm{MHz}$ and $3-\mathrm{GHz}$ advanced research radars both of which are mounted on the $25-\mathrm{m}$ dish at Chilbolton (see locations plotted later in Fig. 2). The Chilbolton radars alternately made low-elevation plan-position indicator (PPI) scans and series of range-height indicator (RHI) scans. Because of the large dish and high power (560 $\mathrm{kW}$ ), the $3-\mathrm{GHz}$ radar is very sensitive and was used to map not only areas of very light precipitation but also clear-air (and cloudy) features, such as the edges of thermals and developing cumulus convection and the stable layer capping them. Observational data from the different instruments are synthesized in this paper to produce a detailed picture of the atmosphere during the development of the convection in IOP 1 . It shows how upper-level and boundary layer mechanisms can combine to increase potential instability and raise a capping inversion locally to a sufficient degree to allow deep convection to form in a single preferred location. Although we make use of NWP model data to back up our interpretation of the observations, no modeling experiments will be described here. Modeling experiments to investigate the sensitivity of the convective development to various factors will be presented in subsequent papers.

\section{General situation}

The operational Met Office surface analysis for 1200 UTC 15 June 2005 (CSIP IOP 1), is shown in Fig. 1. There is a low pressure center located to the northwest of the United Kingdom, which led to a southwesterly flow over southern United Kingdom where the various 


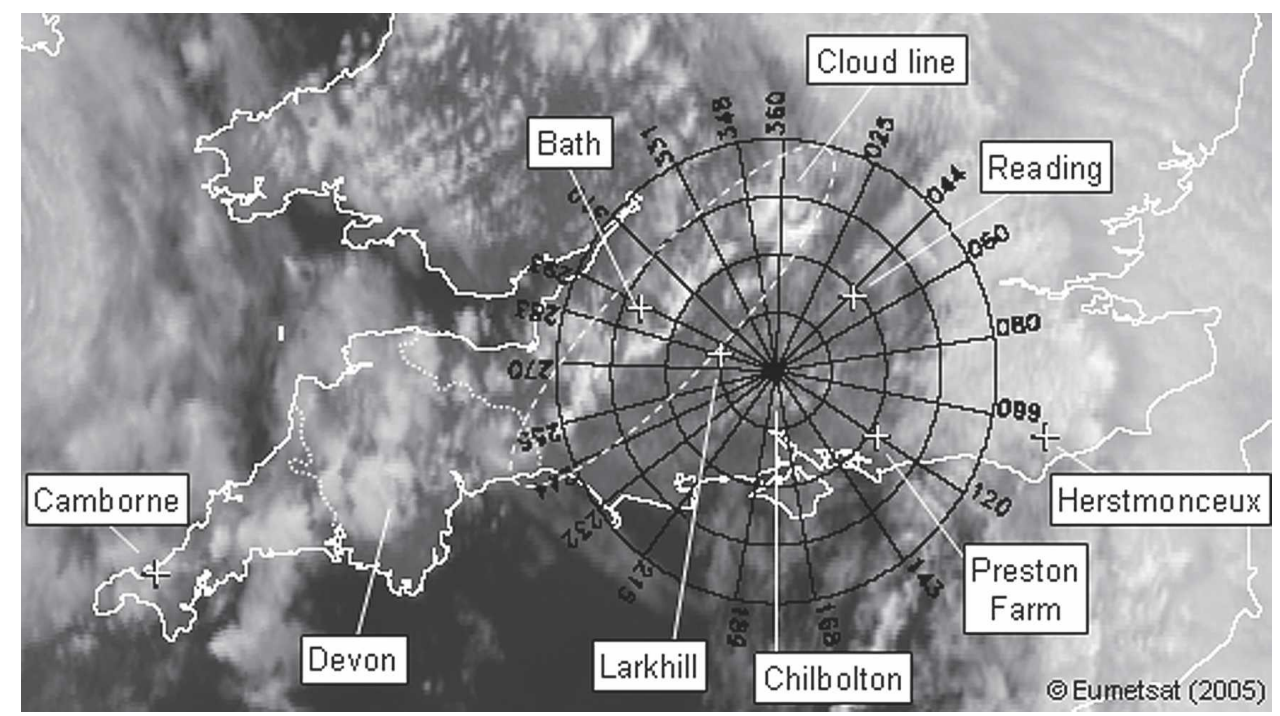

FIG. 2. High-resolution visible imagery at 1200 UTC 15 Jun 2005 from Meteosat-8. The sites from which radiosondes were launched are indicated by white crosses: (from left to right) Camborne, Bath, Larkhill, Reading, Preston Farm, and Herstmonceux. The black circle, which has a radius of $100 \mathrm{~km}$ and is centered on Chilbolton, indicates the maximum range of the 3-GHz radar at Chilbolton. The radial lines and digits indicate the azimuths along which RHIs were performed. The boundaries of the county of Devon are indicated by dotted white lines. The dashed white ellipse highlights the cloud line mentioned in the text.

observational instruments were deployed. An occluded front has been analyzed over eastern England and an upper-level trough is located over the south of Ireland.

In the southwesterly flow between the occluded front and ensuing trough, a series of light showers, with rain rates up to $8-16 \mathrm{~mm} \mathrm{~h}^{-1}$, formed in a line emanating from Devon, in the southwest of the United Kingdom. One of these light showers developed into a cluster of deep convective showers within range of the advanced meteorological research radars at Chilbolton $\left(51.14^{\circ} \mathrm{N}\right.$, $1.44^{\circ} \mathrm{W}$; Goddard et al. 1994). The radar observations collected on this day have allowed us to gain insight into the evolution of the atmosphere that accompanied the transition of the convection from small shallow showers, with modest rain rates, to a small cluster of deep convective cells, producing heavy rain and lightning.

Figure 2 shows the high-resolution visible image from Meteorological Satellite (Meteosat) 8 at 1200 UTC (Schmetz et al. 2002). A line of clouds approximately 8 $\mathrm{km}$ wide and around $150 \mathrm{~km}$ long, with a well-defined southeastern edge, has formed downwind of Devon. Figure 3 shows an analysis of the $10-\mathrm{m}$ wind vectors and convergence at 1000 UTC. These were produced as part of the Nimrod system by combining surface observations and NWP model data (Golding 1998). The line of clouds highlighted in Fig. 2 has formed in a region where convergent southwesterly flow has persisted for several hours. Figure 4 shows the precipitation associated with the clouds that formed along this line. The PPI of the radar reflectivity factor (hereafter simply "reflectivity") for the sector to the west of Chilbolton at 1152 UTC shows that most of the showers were producing only light rain with reflectivities of little more than $30 \mathrm{dBZ}$. Radar vertical cross sections indicate that these showers were around $3.5 \mathrm{~km}$ deep, which is below the $0^{\circ} \mathrm{C}$ level, and hence precipitation growth did not involve the ice phase. Because the differential reflectivity was close to zero, there probably were a relatively large number of small drizzle drops in these showers, so that, using an appropriate $Z-R$ relationship (Collier 1996), this implies rainfall rates of up to $5 \mathrm{~mm} \mathrm{~h}^{-1}$. In comparison, the cluster of showers to the north of Chilbolton, which constitutes the storm of interest, had reflectivities up to $52 \mathrm{dBZ}$, and the radar vertical cross sections indicate that these showers were over $7 \mathrm{~km}$ deep at this time. A comparison with some thermodynamic soundings suggests that this cluster of showers was deep enough for ice microphysics to have played a part in the growth of precipitation particles. Use of the Marshall and Palmer (1948) relationship would imply a rainfall rate of around $60 \mathrm{~mm} \mathrm{~h}^{-1}$ for this storm. Data from the radar network shows the evolution of this storm's maximum rain rate (Fig. 5). The increase in rain rate around 1100 UTC was closely associated with the transition from shallow to deep convection. A resur- 


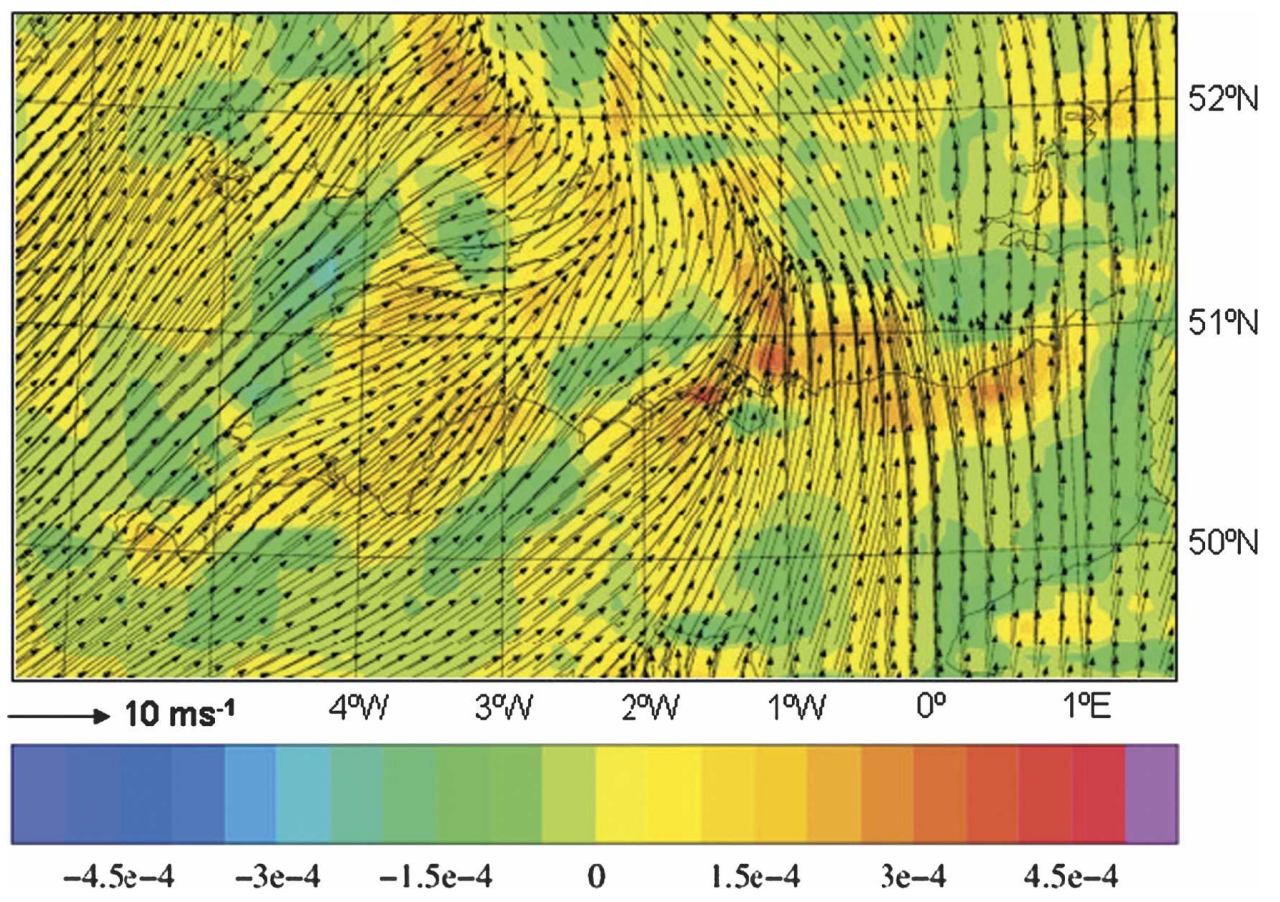

FIG. 3. Analysis of $10-\mathrm{m}$ wind speed $\left(\mathrm{m} \mathrm{s}^{-1}\right)$ and convergence $\left(\mathrm{s}^{-1}\right)$ at 1000 UTC 15 Jun 2005. The area depicted is the same as in Fig. 2.

gence of activity occurred at 1200 and 1240 UTC. The Met Office Arrival Time Difference (ATD) system (Lee 1990) detected lightning at 1240 UTC.

There are two themes in this study-one is the formation of the shallow convection and light rain showers, while the second is the transition to deep convection to give an isolated thunderstorm with higher rain rates. A good forecast for such a case requires correctly representing the two different convective regimes as well as the change from one to the other. This is a challenge for a NWP model but the very high resolution model used was successful in this case.

\section{Use of model diagnostics to support the observational analysis}

In this study we make use of data from four different NWP models. Two of these, the European Centre for Medium-Range Weather Forecasts (ECMWF) model and the global version of the Met Office Unified Model, are used for large-scale analysis. Two others are used for more detailed analysis. One of these is the operational 12-km version of the Met Office Unified Model (Cullen 1993). This model is nonhydrostatic (Davies et al. 2005) and has a convection scheme based on Gregory and Rowntree (1990). Finally, we also use data from a $1.5-\mathrm{km}$ grid length version of the same model, which, due to its high resolution, is being run without a convection scheme (Clark and Lean 2006). The 1.5-km model is the better model for representing the development and life cycle of the convective showers because, unlike the $12-\mathrm{km}$ model with parameterized convection, actual convective circulations can develop, giving the model some memory of the dynamics of the storms.

Figure 6a shows an early stage in the development of the isolated storm in IOP 1 as seen by the operational radar network at 1100 UTC. The operational radars have a lower resolution and a higher minimum detectable threshold than the Chilbolton research radar, and so some of the weaker showers are not depicted in Fig. 6a. Figures 6b,c show the rain-rate forecasts from the 1.5- and 12-km versions of the Met Office Unified Model with a lead time of $11 \mathrm{~h}$. In all three figures there is a frontal rainband present over the east of the country, with some showers behind it to the west. The better representation of the organized line of showers is given by the $1.5-\mathrm{km}$ model, although this model tends to produce too many showers along the convergence line when compared to reality [as shown for other cases by Clark and Lean (2006)]. The convective precipitation in the $12-\mathrm{km}$ model shows no organization on the meso-beta scale (Orlanski 1975). 

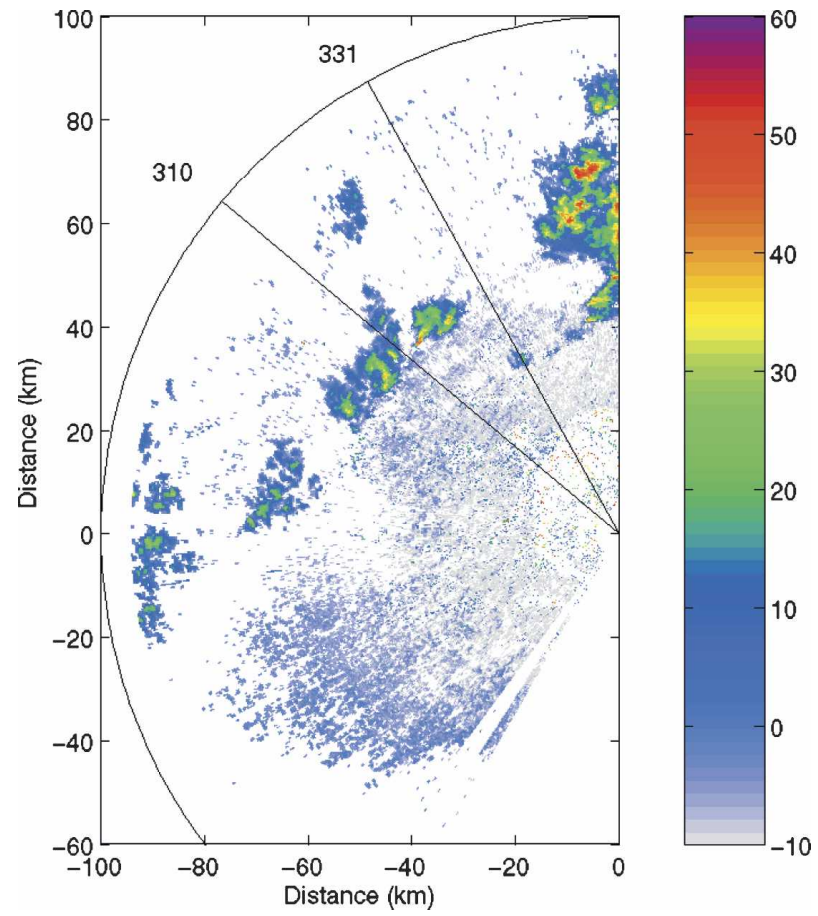

FIG. 4. PPI of reflectivity ( $\mathrm{dBZ})$ at $0.5^{\circ}$ elevation, at $1152 \mathrm{UTC}$ from the $3-\mathrm{GHz}$ Chilbolton radar showing the line of rain showers. The radial lines indicate the orientation of the RHI scans shown in Figs. 10 and 13. The regions of speckled reflectivity less than around $0 \mathrm{~dB} Z$ are due to returns from insects. This scan has been filtered for ground clutter by removing reflectivities with a linear depolarization ratio greater than $-10 \mathrm{~dB}$.
Rain-rate data from the weather radar network were used to track the small cluster of heavy showers from when it first appeared on the radar network to when it left the area covered by the $3-\mathrm{GHz}$ radar at Chilbolton (Fig. 7a). Figure 7b, shows a similar analysis for the track of the single cluster of heavy showers that formed in the $1.5-\mathrm{km}$ model. To ensure a fair comparison, the rain rate from the $1.5-\mathrm{km}$ model was averaged onto a $5-\mathrm{km}$ grid equivalent to that used by the radar network. Precipitation from the cluster of showers that went on to become the storm was first detected by the radar network at 0915 UTC; the model started producing rain 15 min earlier. The location of first precipitation was about $15 \mathrm{~km}$ in error; this error had components of 8 $\mathrm{km}$ along and $12 \mathrm{~km}$ across the direction of storm motion, corresponding, respectively, to the errors in the timing of synoptic features or the detailed initiation, and the location of the convergence line. The speed of motion of the storm in the model $\left(47 \pm 1 \mathrm{~km} \mathrm{~h}^{-1}\right)$ agreed with that from the radar network observations $\left(48 \pm 1 \mathrm{~km} \mathrm{~h}^{-1}\right)$ within the limits of measurement error. Additionally, the storm trajectories deviated by less than the diameter of the storm after $4 \mathrm{~h}$. The similarities in the time and location of first precipitation, and motion of the observed and modeled storms, give us confidence that the $1.5-\mathrm{km}$ model was performing well on this day. We shall therefore make use of detailed diagnostics from the $1.5-\mathrm{km}$ model to support our interpretation of the observations.

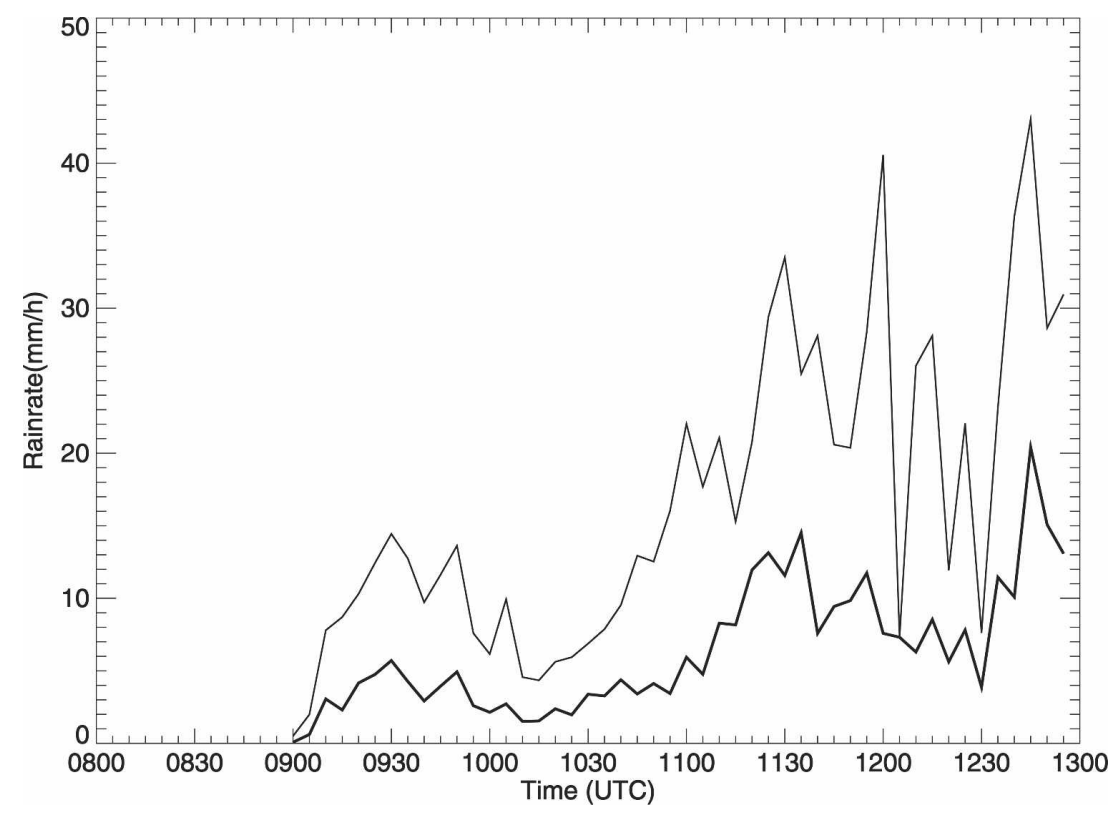

FIG. 5. Time series from the radar network of the maximum rain rate for the shower of interest averaged onto a $2-\mathrm{km}$ grid (thin line) or 5-km grid (bold line). 

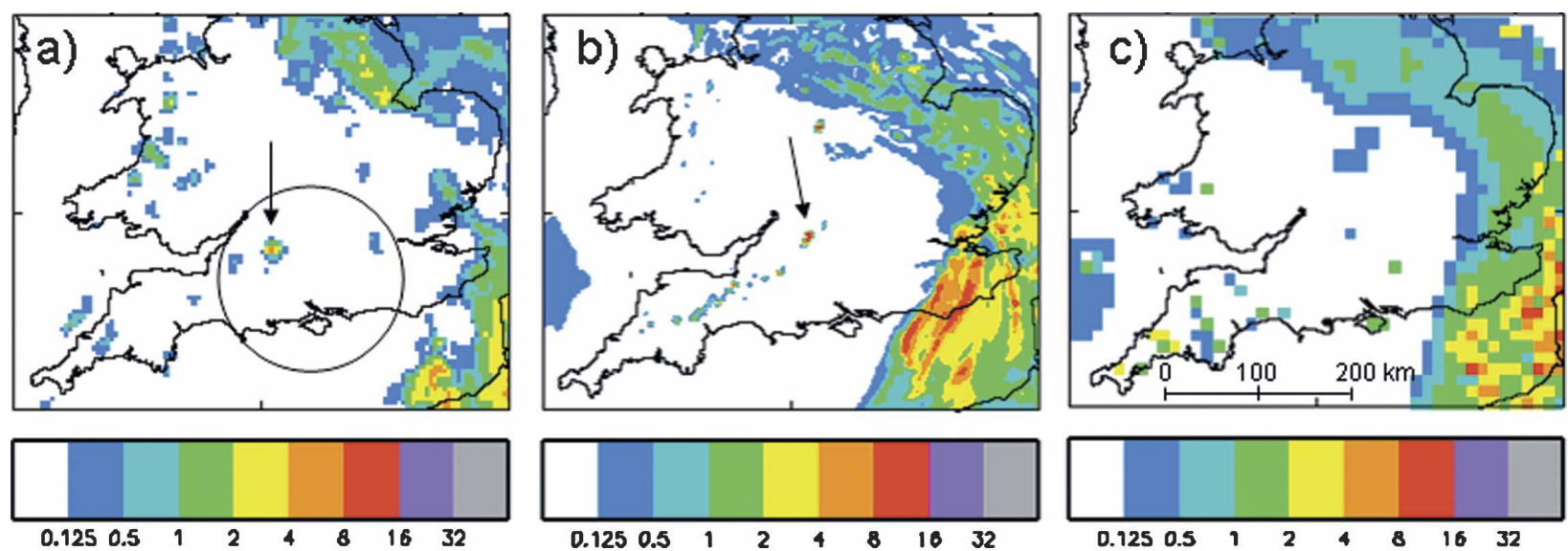

FIG. 6. Rain rate at 1100 UTC 15 Jun 2005: (a) as observed by the weather radar network and as forecast by (b) the 1.5-km and (c) $12-\mathrm{km}$ versions of the Unified Model. The circle in (a) shows the 100-km range of the advanced meteorological radar at Chilbolton. The arrows in (a) and (b) indicate the thunderstorm of interest.

\section{The lid and its lifting by low-level convergence downwind of Devon}

Figure 8 shows a thermodynamic profile in the vicinity of the line of convective showers. The tephigram for the radiosonde launched from Bath at 1104 UTC, about $20 \mathrm{~km}$ west of the main shower at this time, is shown in Fig. 8a. Figure $8 \mathrm{~b}$ shows the profile from the $1.5-\mathrm{km}$ model for the same time and place. Features of interest from the profiles include (i) an inversion at $500 \mathrm{hPa}$ in the observations and a corresponding stable layer beginning at $440 \mathrm{hPa}$ in the model (actually a tropopause fold, as discussed later); (ii) a dry stratospheric intrusion above $500 \mathrm{hPa}$; and (iii) a dry intrusion between 750 and $550 \mathrm{hPa}$, the base of which constituted a lid at
$750 \mathrm{hPa}(725 \mathrm{hPa}$ in the model). The path of a nearsurface parcel is depicted by a gray line in Fig. 8a. Using a value of $\theta_{w}=14^{\circ} \mathrm{C}$ for this parcel, the convective inhibition (CIN) of the lid between 750 and $600 \mathrm{hPa}$ was $85 \mathrm{~J} \mathrm{~kg}^{-1}$. At this stage the height of the showers was being capped by this lid, limiting their depth to less than $3 \mathrm{~km}$.

The humidity and temperature gradients found at the base of the lid correspond to changes in the atmospheric index of refraction (Fig. 9a). Gradients in refractive index can be detected by radar (e.g., Gossard and Strauch 1983). Figure 9b shows the square of the vertical gradient of the refractive index and suggests that clear-air echoes would have been expected from an altitude of around $2.4 \mathrm{~km}$ (Gossard et al. 1998). The
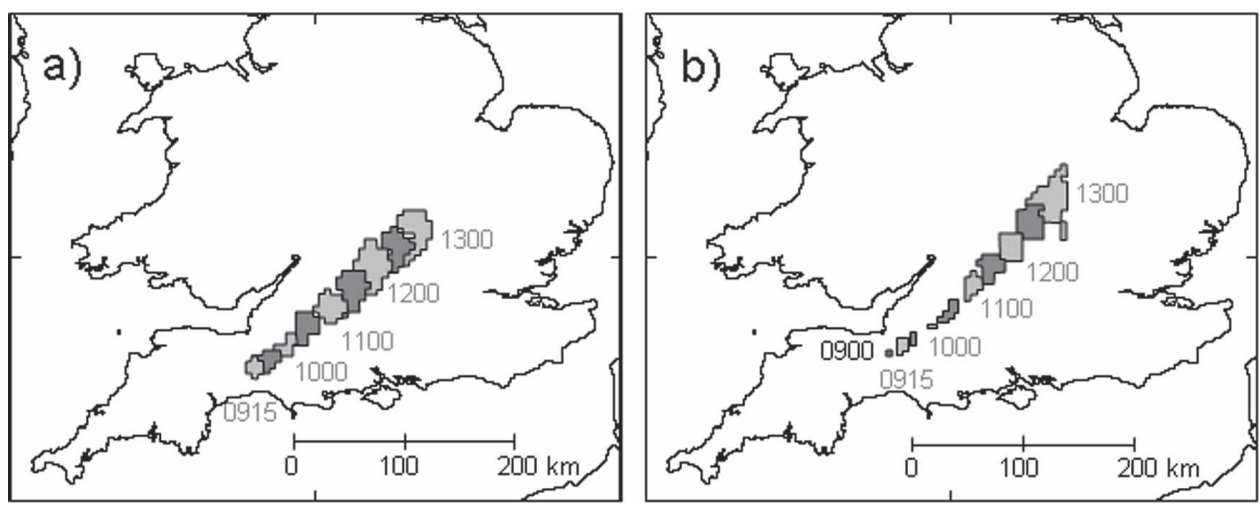

FIG. 7. The track of the developing thunderstorm is shown by the outline of the precipitating region (a) as measured by the radar network from 0915 UTC when the first echo appears to 1300 UTC when it moves out of range of the Chilbolton radar and (b) as forecast by the $1.5-\mathrm{km}$ model. The precipitating region is shaded alternately light and dark gray for clarity. Both storms have a speed of around $48 \mathrm{~km} \mathrm{~h}^{-1}$. 


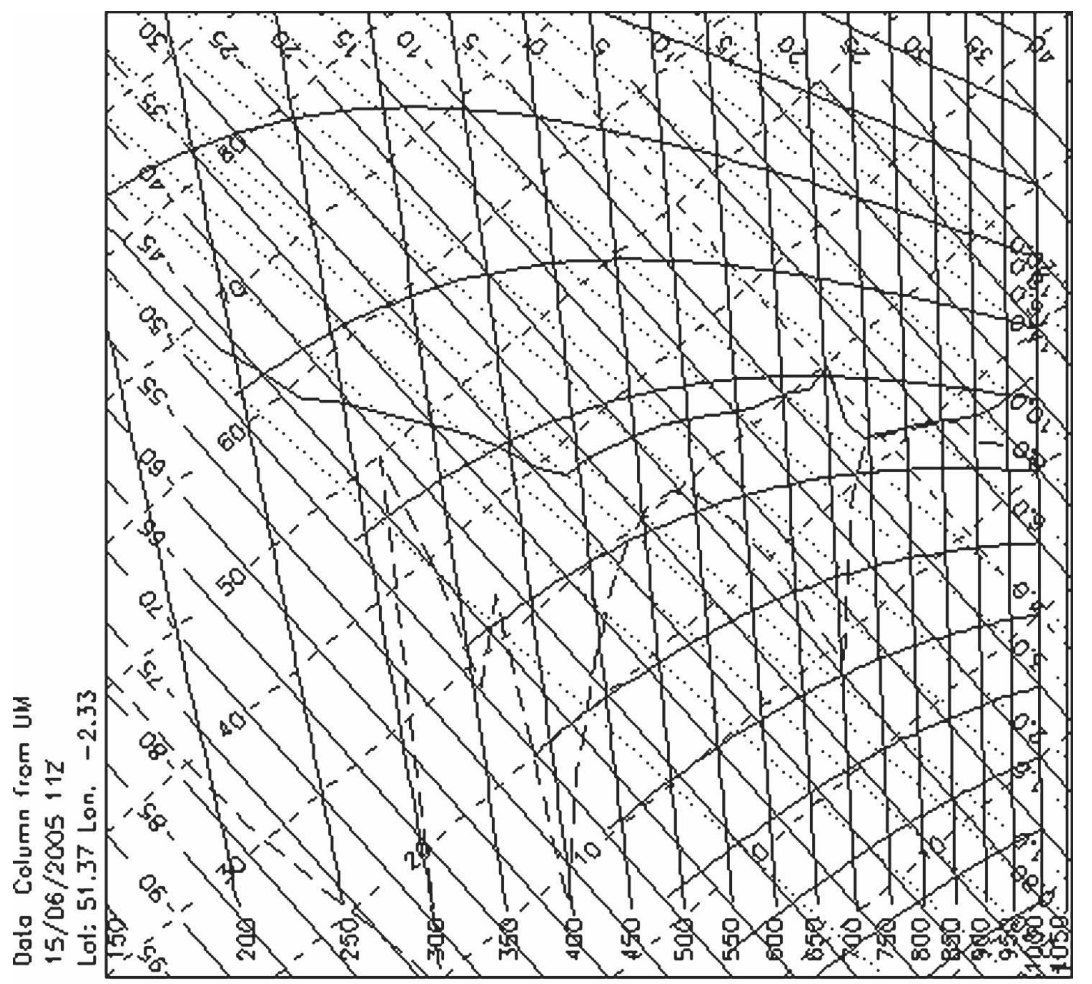

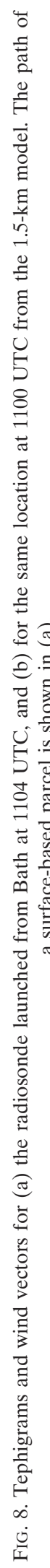
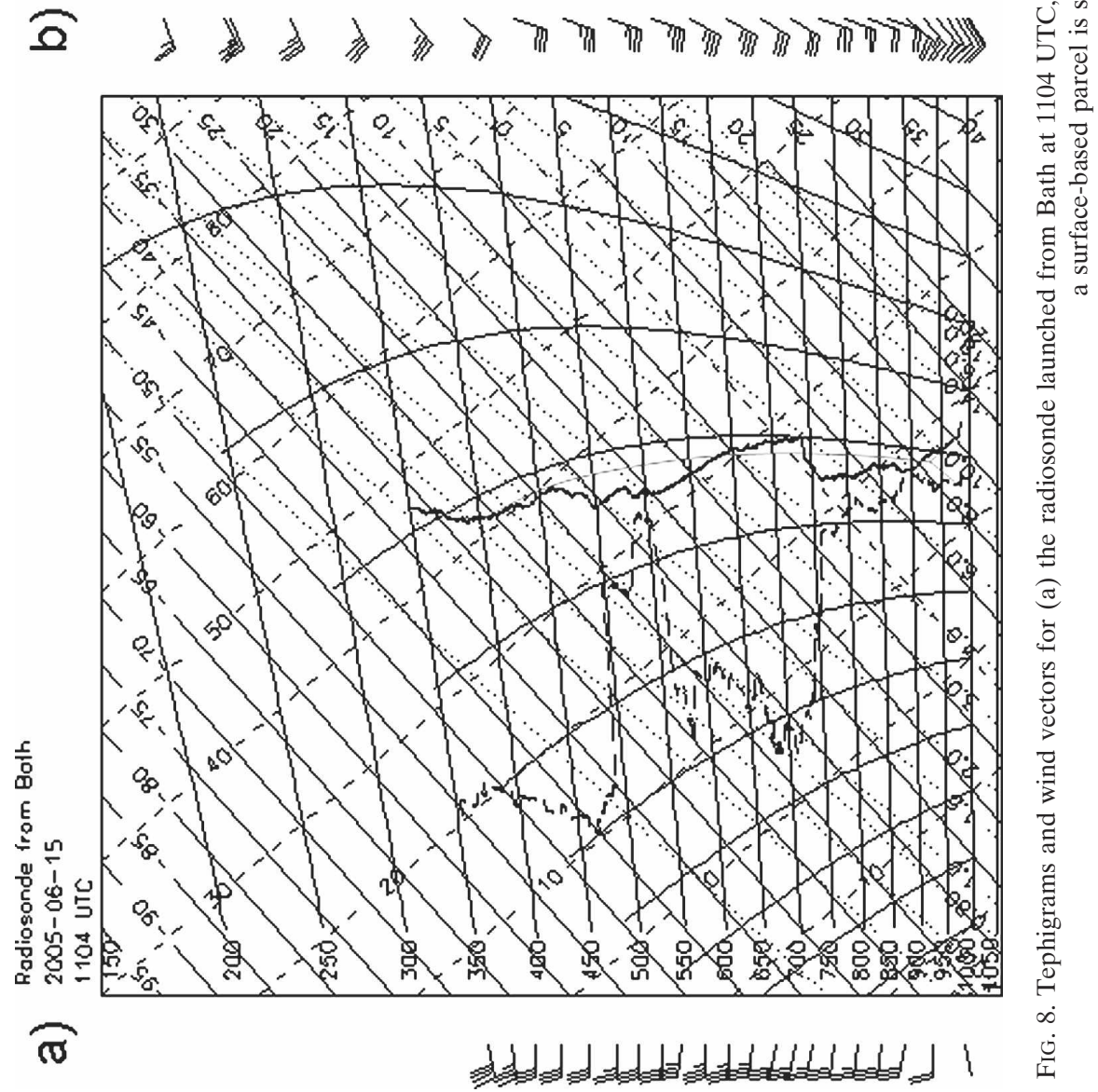


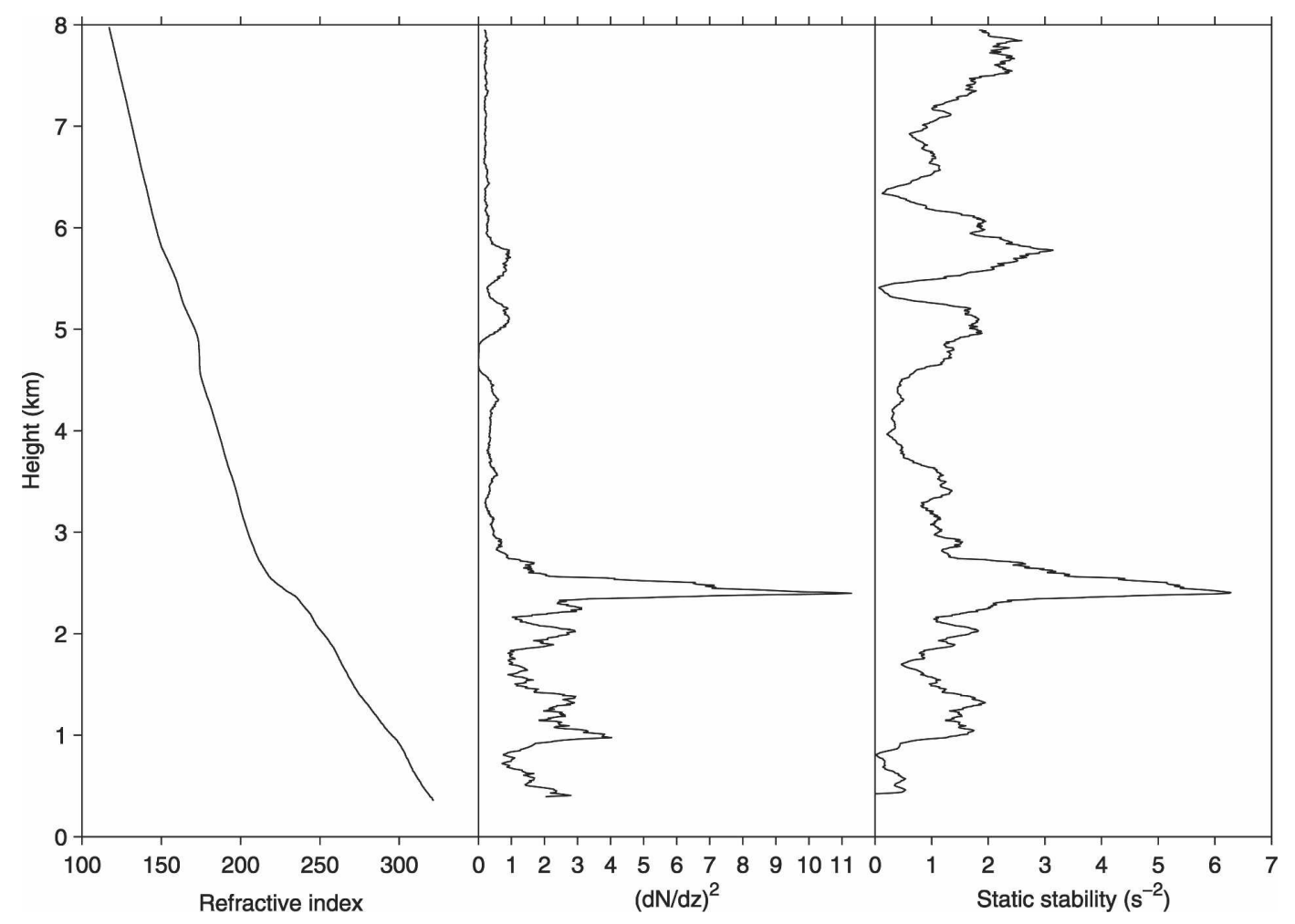

FIG. 9. Diagnostics calculated for the radiosonde launched from Bath at 1100 UTC: (a) refractive index, (b) square of the vertical gradient of the refractive index $\left(\times 10^{-3}\right)$, and $(c)$ static stability $\left(\times 10^{-4}\right)$.

profile of static stability $N^{2}=\left(g / \theta_{0}\right) \partial \theta / \partial z$, shown in Fig. $9 \mathrm{c}$, confirms that the clear-air echo would occur at a similar height as the stable region forming the lid.

Rayleigh scattering from particulates and Bragg scattering resulting from fluctuations in the refractive index have different wavelength dependence (Gossard and Strauch 1983). As a result, when considering a dualwavelength radar system calibrated for Rayleigh scattering, there will be a difference in the reflectivities resulting from Bragg scatter at the two wavelengths. The two radars at Chilbolton operate at $1275 \mathrm{MHz}(\mathrm{L}$ band) and $3.077 \mathrm{GHz}$ (S band). Consequently, reflectivity resulting from Bragg scatter will be $14.0 \mathrm{dBZ}$ higher at $\mathrm{L}$ than at $\mathrm{S}$ band. Figures 10a,b show RHIs at 1115 UTC, along $331^{\circ}$, at S and L band. Both scans show a thin layer of increased reflectivity between the 10 - and $18-\mathrm{km}$ range and at around $2-\mathrm{km}$ altitude (within the black boxes). The convective showers, reaching a height of $7 \mathrm{~km}$, will be discussed in section 5 . Figure 11 shows a scatterplot of reflectivity at $\mathrm{L}$ and $\mathrm{S}$ band for the RHIs at 1115 UTC. Because of the different sampling volumes of the two radars $\left(0.75^{\circ} \times 66 \mathrm{~m}\right.$ and $0.28^{\circ} \times 300 \mathrm{~m}$, respectively), the data have been linearly averaged to a coarser resolution $\left(0.75^{\circ} \times 300\right.$ $\mathrm{m})$ for the comparison. This difference in beamwidth explains why the layer echo seen beyond the $20-\mathrm{km}$ range by the S-band radar, is no longer seen by the L-band radar. In Fig. 11, the data collected within the boxed regions in Figs. 10a,b, corresponding to the layer of increased reflectivity, are plotted as circles, while all other data are plotted using crosses. The solid line in Fig. 11 shows the one-to-one relationship along which data resulting from Rayleigh scatter are expected to lie. The dotted line, $14.0 \mathrm{dBZ}$ lower, indicates the expected location of data resulting from Bragg scatter.

The presence of crosses below the one-to-one line suggests that Bragg scatter is contributing to the reflectivity in regions other than the layer echo. The other sources of Bragg scatter include the 1-km-deep thermals between the 20 - and $35-\mathrm{km}$ range, and the edges of the clouds and showers. As a group, the circles from the boxed region around the layer echo have a reflectivity $16 \pm 3 \mathrm{dBZ}$ higher at $\mathrm{L}$ band than at $\mathrm{S}$ band. This suggests that the layer of increased reflectivity is due to Bragg scatter from the inversion seen in the thermodynamic sounding, and not Rayleigh scatter from particulates such as insects, cloud droplets, or raindrops, which would result in the same reflectivity at both wavelengths.

An RHI of 3-GHz radar reflectivity, along azimuth 

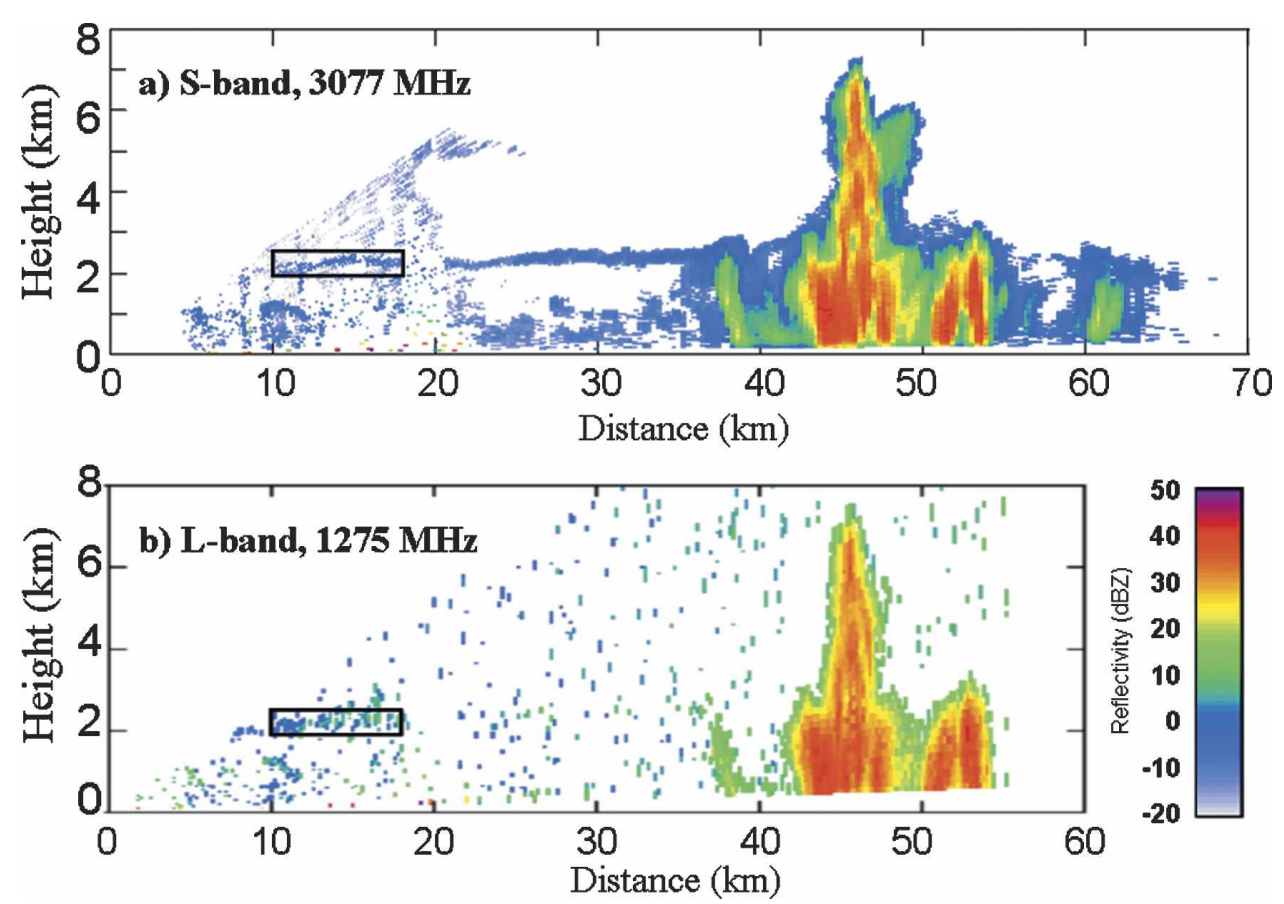

FIG. 10. (a) RHI of reflectivity (dBZ) along $331^{\circ}$ at 1115 UTC from the $3-\mathrm{GHz}$, S-band, Chilbolton radar showing convection having broken through the lid and reaching a height of $7 \mathrm{~km}$. This scan is perpendicular to the cloud street shown in Fig. 2 and transects the small patch of heavy showers shown to the north of the radar in Fig. 4. The box between 10- and 18- $\mathrm{km}$ range and 1.9- and 2.5-km altitude identifies the layer of increased reflectivity, which a dual-wavelength comparison showed was due to Bragg scatter. This scan has been filtered for ground clutter by removing reflectivities with a linear depolarization ratio greater than $-10 \mathrm{~dB}$. (b) RHI of reflectivity (dBZ) along $331^{\circ}$ at $1115 \mathrm{UTC}$ from the $1275-\mathrm{MHz}$, L-band, Chilbolton radar. The box between 10- and 18-km range and 1.9- and 2.5-km altitude identifies the layer of increased reflectivity used in the dual-wavelength comparison. In this image, a signal-to-noise threshold of $2.2 \mathrm{dBZ}$ has been used to filter residual noise after spectral processing.

$283^{\circ}$ at 1037 UTC, is shown in Fig. 12a. The RHI shows some of the showers that later developed into deep convection located at a range of between 48 and $60 \mathrm{~km}$. Figure 12a also shows a layer of clear-air echo resulting from changes in the atmospheric refractive index at the height of the lid (strictly the echo is mainly from the base of the lid, but elsewhere for simplicity we ignore this distinction). Figure $12 \mathrm{~b}$ shows a vertical cross section from the $1.5-\mathrm{km}$ model at 1000 UTC, taken perpendicular to the region of raised lid. The shading indicates the dry static stability, and the white contours represent the cloud liquid water content. The maximum in dry static stability was due to the large potential temperature gradient at the height of the lid and corresponds to the peak seen at $2.4 \mathrm{~km}$ in Fig. 9c. The height of the clear-air echo at 1037 UTC at the $70-\mathrm{km}$ range (approximately over Bath) in Fig. 12a is $2.0 \mathrm{~km}$, which is lower than the height of $2.4 \mathrm{~km}$ expected from the radiosonde launched at 1104 UTC (Fig. 9). However, the scan along azimuth $310^{\circ}$ at 1117 UTC, close to where the sonde would have drifted to by the time it got to the height of the lid, shows some clear-air echo at a height of $2.4 \mathrm{~km}$, in good agreement with the radiosonde observations.

Convectively rising boundary layer air had to overcome this lid in order to achieve the transition to deep convection with a level of neutral buoyancy located at the height of the tropopause fold at $500 \mathrm{hPa}$. Thermodynamic profiles from radiosondes launched from Larkhill at 1000 and 1200 UTC and from Bath at 1100 and 1200 UTC (e.g., Fig. 8) suggest that if the lid were to be lifted dry adiabatically by between 500 and $800 \mathrm{~m}$, the lid would effectively be removed and parcels from the surface would be able to convect freely up to the tropopause fold. A key mechanism for such lifting was the convergence line downwind of Devon. Figure 12a shows the lid at $2.2 \mathrm{~km}$ at the $30-\mathrm{km}$ range, being lifted to $3.0 \mathrm{~km}$ at the $55-\mathrm{km}$ range, at this particular time and azimuth, and then falling again to $1.9 \mathrm{~km}$ at the $70-\mathrm{km}$ range. Although the convection seen in this RHI had 


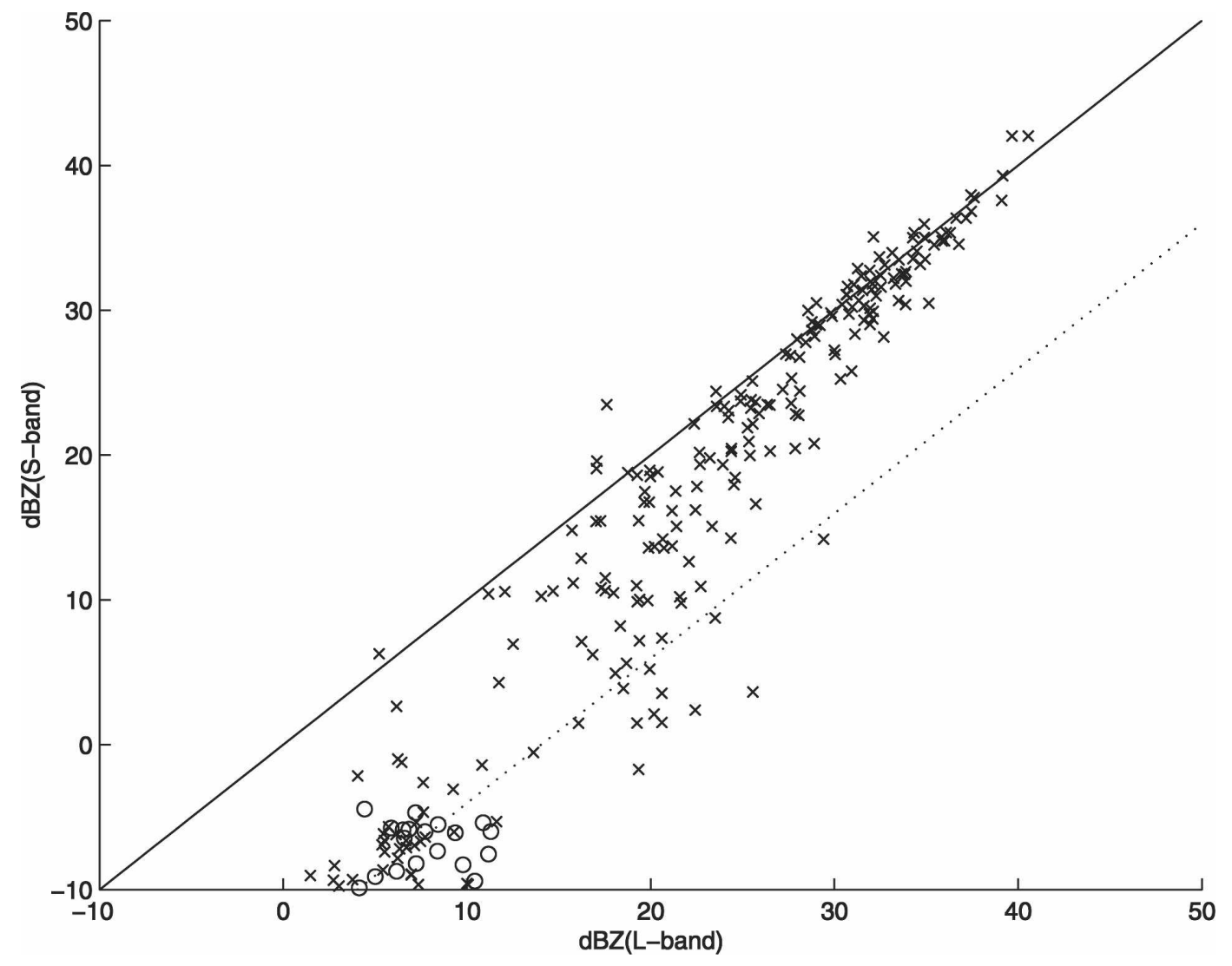

FIG. 11. A dual-wavelength comparison of the reflectivity measured by the $3-\mathrm{GHz}$ (S-band) and $1275-\mathrm{MHz}$ (L-band) radars at 1115 UTC. The reflectivities collected within the boxes shown in Figs. 10a,b, corresponding to the thin echo layers, are plotted using circles, all other data are plotted using crosses.

not broken through the lid, the height over which the lid was being lifted suggests that its breaking was imminent. This is confirmed by the adjacent RHI, just to the north (not shown), where convective plumes had penetrated through the lid.

Convergence lines form downwind of the coast resulting from any of the following three mechanisms: the different frictional forces over the land and sea (Hunt et al. 2004), the different surface temperatures of the land and sea (Simpson 1997), or lifting resulting from orography (Bader et al. 1995), or a combination of all three. In southwesterly wind conditions during the summer, convergence lines tend to form downwind of Devon and Cornwall in the southwest of the United Kingdom (Starr 1997). These convergence lines often lead to lines of cloud and convective showers, and we believe this to have been the case here, because a comparison between Figs. 2, 3, 4, and 6 shows that the locations of the showers seen by the network and Chilbolton radars correspond to the locations of the lines of clouds emanating from Devon in the satellite imagery and the location of the convergence line seen in the 10-m wind analysis. The origins of the convergence line that formed on this day, and a study of the relative importance of the different mechanisms that contributed to its formation are described by H. Lean (2007, unpublished manuscript).

The RHI in Fig. 13 was obtained approximately perpendicularly to the convergence line at the time of Figs. 2 and 4 . Because the convergence was organized along a line, the main contribution to this convergence is likely to have been from confluence at right angles thereto. The Doppler data in Fig. 13a show confluence of around $8 \mathrm{~m} \mathrm{~s}^{-1}$ over a distance of $2.5 \mathrm{~km}$ near the surface and diffluence of around $16 \mathrm{~m} \mathrm{~s}^{-1}$ over a distance of $2.5 \mathrm{~km}$ at around $3-\mathrm{km}$ altitude. The low-level convergence downwind of Devon was lifting the lid. Close to the axis of the line, between the $50-$ and $60-\mathrm{km}$ range in the RHI, the convection extends up to the height of the lid, and the lid itself was raised some more as a result of the ongoing convection. The convection, which in this section led to rain rates around $10 \mathrm{~mm} \mathrm{~h}^{-1}$, corresponds to the area of rain showers approximately $40 \mathrm{~km}$ southwest of the main storm cluster shown to 

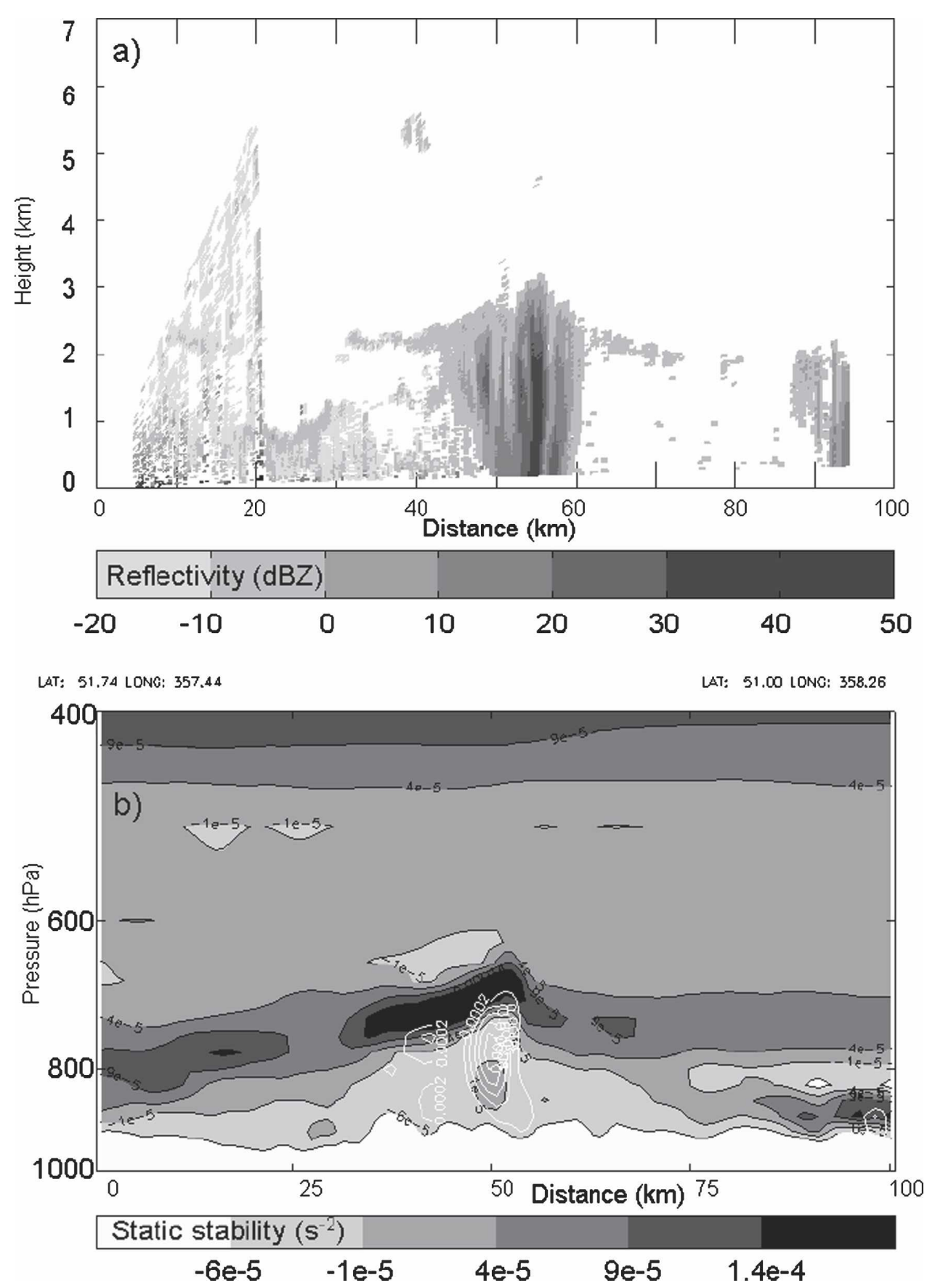

FIG. 12. (a) RHI of reflectivity (dBZ) from the $3-\mathrm{GHz}$ radar at Chilbolton at 1037 UTC along an azimuth of $283^{\circ}$, as indicated by the white dashed line in Fig. 14a. This scan has been partially filtered for ground clutter by removing reflectivities with a linear depolarization ratio greater than $-10 \mathrm{~dB}$. (b) Vertical cross section of static stability $\left(\mathrm{s}^{-2}\right)$ showing the lifting of the lid in the region of the convergence line. The white contours, at $0.2 \mathrm{~g} \mathrm{~kg}^{-1}$ intervals, show liquid water content to highlight the location of the convection.

the north of Chilbolton in Fig. 4. Figure 13b shows that to the side of this convergence line there is some boundary layer convection, which is revealed by the lumpy layer beneath the lid echo (seen most clearly between the 28- and 48-km range). Although there are occasional plumes that do reach the height of the lid (e.g., at the 26- and 33-km range), most of the boundary layer convection does not. 

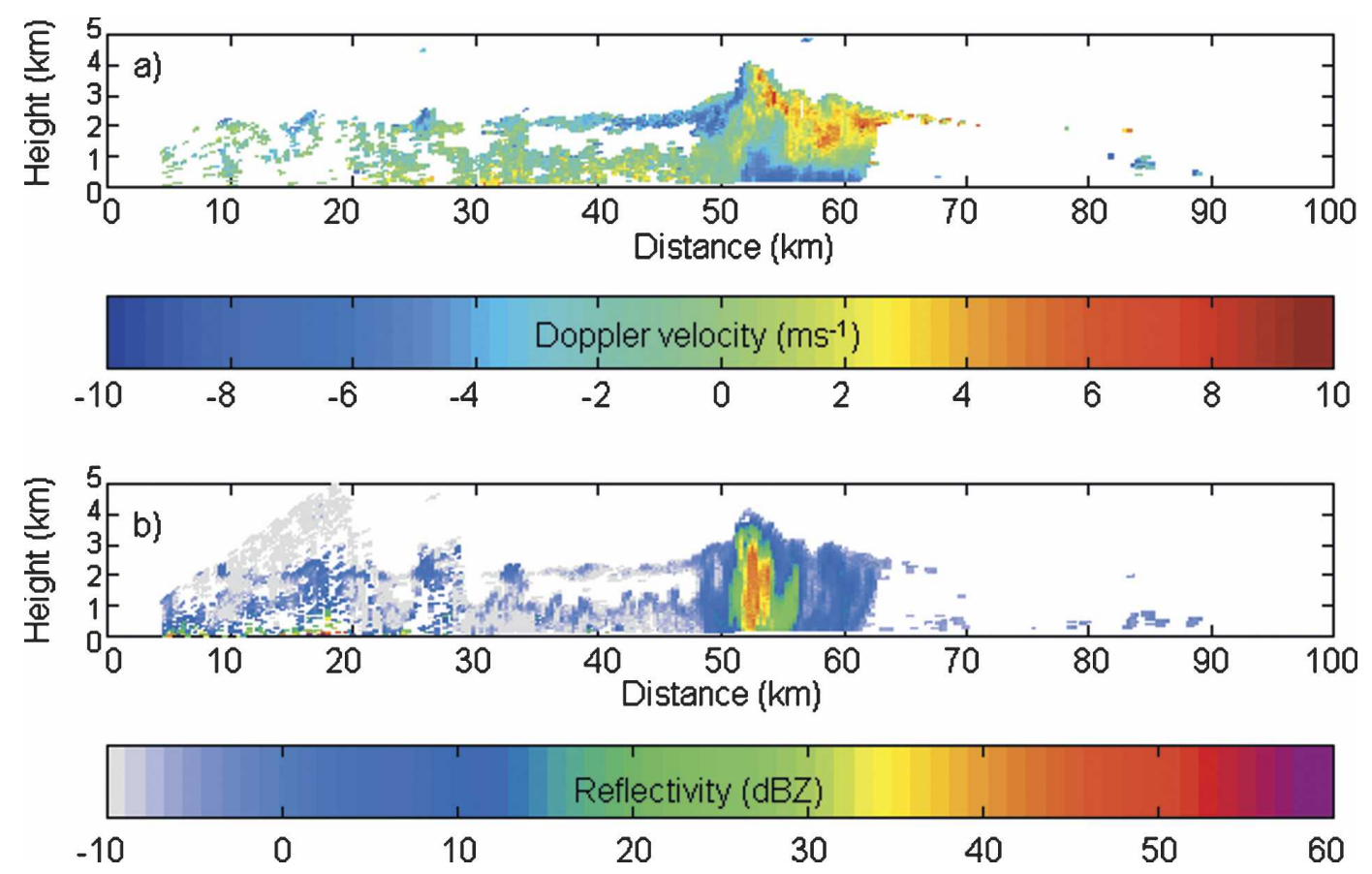

FIG. 13. RHI scans from the $3-\mathrm{GHz}$ radar at Chilbolton, along azimuth $310^{\circ}$ at $1200 \mathrm{UTC}$ : (a) Doppler velocity $\left(\mathrm{m} \mathrm{s}^{-1}\right.$, positive away from the radar) and (b) reflectivity $(\mathrm{dBZ})$. This scan is perpendicular to the cloud street shown in Fig. 2 and transects the light showers shown in Fig. 4. These scans have been filtered for ground clutter by removing reflectivities with a linear depolarization ratio greater than $-10 \mathrm{~dB}$.

Having presented three examples of 3-GHz radar reflectivity RHIs showing thin clear-air-layer echoes (Figs. 10a, 12a, and 13b), we shall now make use of a series of RHI scans showing similar clear-air echoes to map the height of the lid. During CSIP in 2005, the scanning sequence for the $25-\mathrm{m}$ dish consisted of 20 RHIs at approximately $18^{\circ}$ azimuth apart, followed by a low-level $360^{\circ} \mathrm{PPI}$ (the whole sequence taking around $43 \mathrm{~min}$ ). The RHI scans were performed up to an elevation of $15^{\circ}$ and the elevation scan rate was a function of elevation with a value of $0.1^{\circ} \mathrm{s}^{-1}$ at $15^{\circ}$ elevation, decreasing smoothly to $0.02^{\circ} \mathrm{s}^{-1}$ below $4^{\circ}$ elevation to enable better detection of finescale vertical structures at long range. The height of the lid, subjectively defined as the height of the maximum in the clear-air reflectivity layer, was recorded manually at 5 -km-range intervals. Because of the time taken to complete a sequence of 20 RHI scans, the locations of the data points have been advected by the system velocity $\left(48 \mathrm{~km} \mathrm{~h}^{-1}\right.$ toward the northeast) to create a distribution at a standardized time. The objective analysis technique described by Barnes (1964) was then used to draw smooth contours through the irregularly spaced data points. This method of producing a horizontal map of the height of a stable layer by looking at a series of radar RHI scans showing clear-air reflectiv- ity has already been described by Morcrette et al. (2006), but they used data from the $1275-\mathrm{MHz}$ (L band) radar also mounted on the 25-m antenna at Chilbolton. Although the longer wavelength at $\mathrm{L}$ band makes it preferable for detecting clear-air signals, the $0.75^{\circ}$ beamwidth makes the detection of weak signals at long range difficult. In contrast, the $0.28^{\circ}$ beamwidth of the S-band radar, when combined with the reduced scan rate at low elevation used in 2005, improved the ability of that radar to resolve shallow echoes at low altitude and enabled useful clear-air signals to be detected over a wider area.

Figure 14a shows the resulting map of the height of the lid at 1100 UTC, derived from 20 RHIs collected between 1028 and 1103 UTC. The digits indicate the height of the lid in hundreds of meters, while the shading is the result of the Barnes analysis. The white regions are too distant from observations to allow a reliable interpolated value to be calculated. When carrying out the Barnes analysis to produce the smooth field from discrete data in Fig. 14a, each data point was set to exert an influence over a surrounding area defined as a Gaussian function with a user-specified width. After experimenting with full-widths-at-half-maximum (FWHM) of 10, 20, and $30 \mathrm{~km}$, it was found that using $30 \mathrm{~km}$ resulted in fields that were too smooth. Using a 
(a)

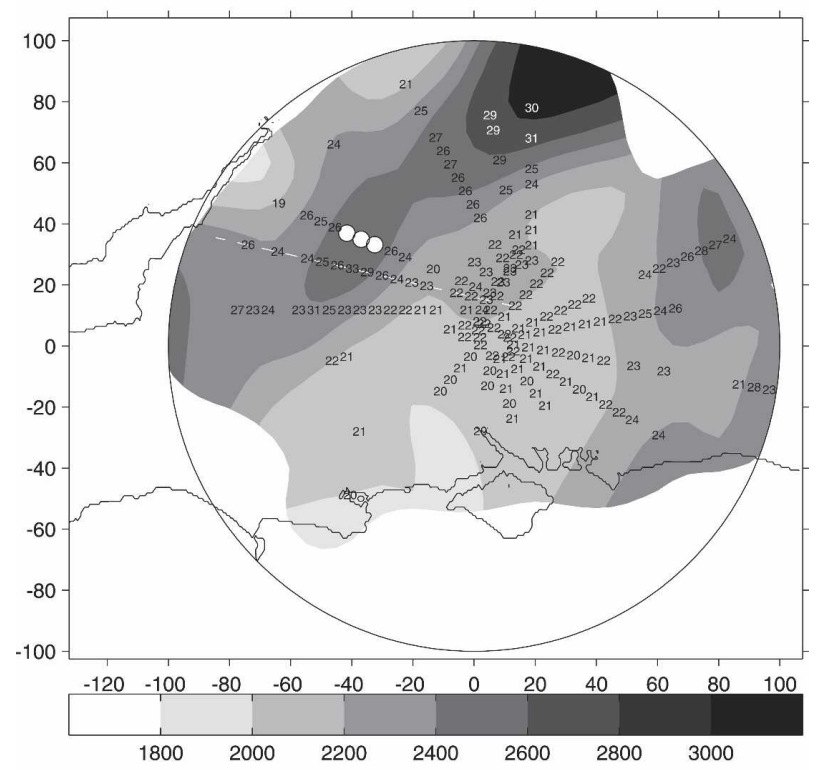

(b)
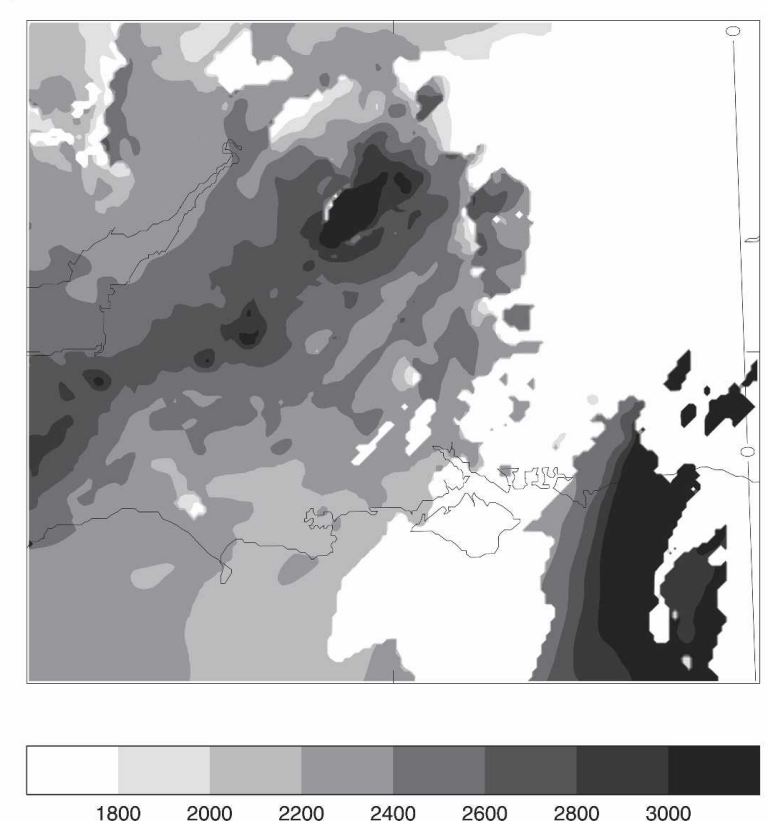

FIG. 14. Plan view of the height $(\mathrm{m})$ of the lid capping the boundary layer convection at 1100 UTC: (a) derived from 20 RHI between 1028 and 1103 UTC, and (b) from the 1.5-km model. In (a) the observed system velocity has been used to correct the location of the data, and the broken white line indicates the location of the vertical cross section along azimuth $283^{\circ}$ shown in Fig. 12a. The numbers $\left(\times 10^{2} \mathrm{~m}\right)$ indicate the observations. The white dots indicate the locations of convective elements penetrating the lid. In (b) the large white area is where the boundary layer is shallow because of the presence of the front.
FWHM of 10 or $20 \mathrm{~km}$ confirmed the presence of an elongated ridge of higher lid height oriented in a southwest-to-northeast direction. However, using a FWHM of $10 \mathrm{~km}$ caused the radial distribution of data to become apparent in the final fields, while using a FWHM of $20 \mathrm{~km}$ created gradients across the ridge that were too smooth when compared to the radar RHIs, showing the rising and falling of the lid (e.g., Fig. 12a). The FWHM was consequently set to $10 \mathrm{~km}$ across the direction of the convergence line and $20 \mathrm{~km}$ along it with a sinusoidal variation in between.

Figure 14a shows that the height of the lid varied from less than $2 \mathrm{~km}$ to the south of the radar to over 2.6 $\mathrm{km}$ to the northwest where the convergence line has lifted the lid over a band downwind of Devon. The variation in the height of the lid seen in the analysis in Fig. 14a corresponds to the rise and fall in the height of the clear-air echo seen, for example, along azimuth $283^{\circ}$ in Fig. 12a, the time-corrected location of which is indicated by the white line in Fig. 14a. The white circles in Fig. 14a indicate the locations in one of the RHIs (along azimuth $293^{\circ}$ at 1036 UTC) where narrow convective plumes are observed to have penetrated the stable layer. The locations of the convective plumes have also been advected to where they would be at 1100 UTC. These plumes are seen in a region where the lid has been lifted and weakened. The lifting of the capping inversion in a band downstream of Devon is also seen in the $1.5-\mathrm{km}$ model (Fig. 14b). In the case of the model, the height of the lid has been diagnosed by searching for the height of the maximum in dry static stability occurring between the surface and $500 \mathrm{hPa}$. The region in Fig. 14a where convective plumes were penetrating the stable layer is close to the region in the model where the height of the lid was greatest.

In summary, it has been shown that the light showers that formed on this day did so along a convergence line emanating from Devon. The effect of low-level convergence was to raise the height of the lid capping convection over a band a few tens of kilometers wide. Showers with mainly modest rain rates developed in this band. However, the small area of showers seen in Fig. 14a to have been more vigorous than the others, continued to intensify and this is described next.

\section{Penetration of convection through the lid}

Figure 10 shows an RHI at 1115 UTC along 331 through the same cluster of showers as depicted $38 \mathrm{~min}$ earlier in Fig. 12a, and it shows that the convection had reached a depth of over $7 \mathrm{~km}$ by this time. Figure 15 shows a vertical cross section of dry static stability from 


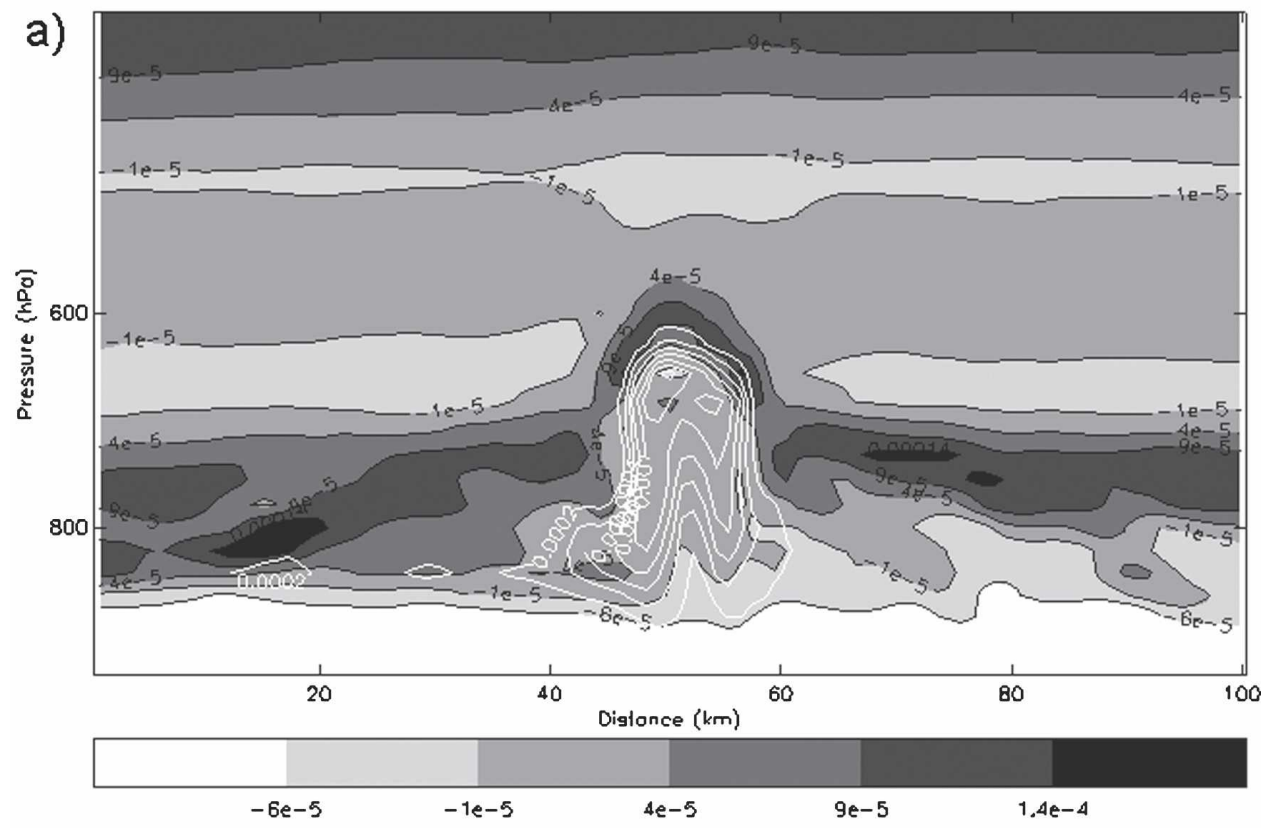

LAT: 52.24 LONG: 358.22

LAT: 51.55 LONO: 359.07

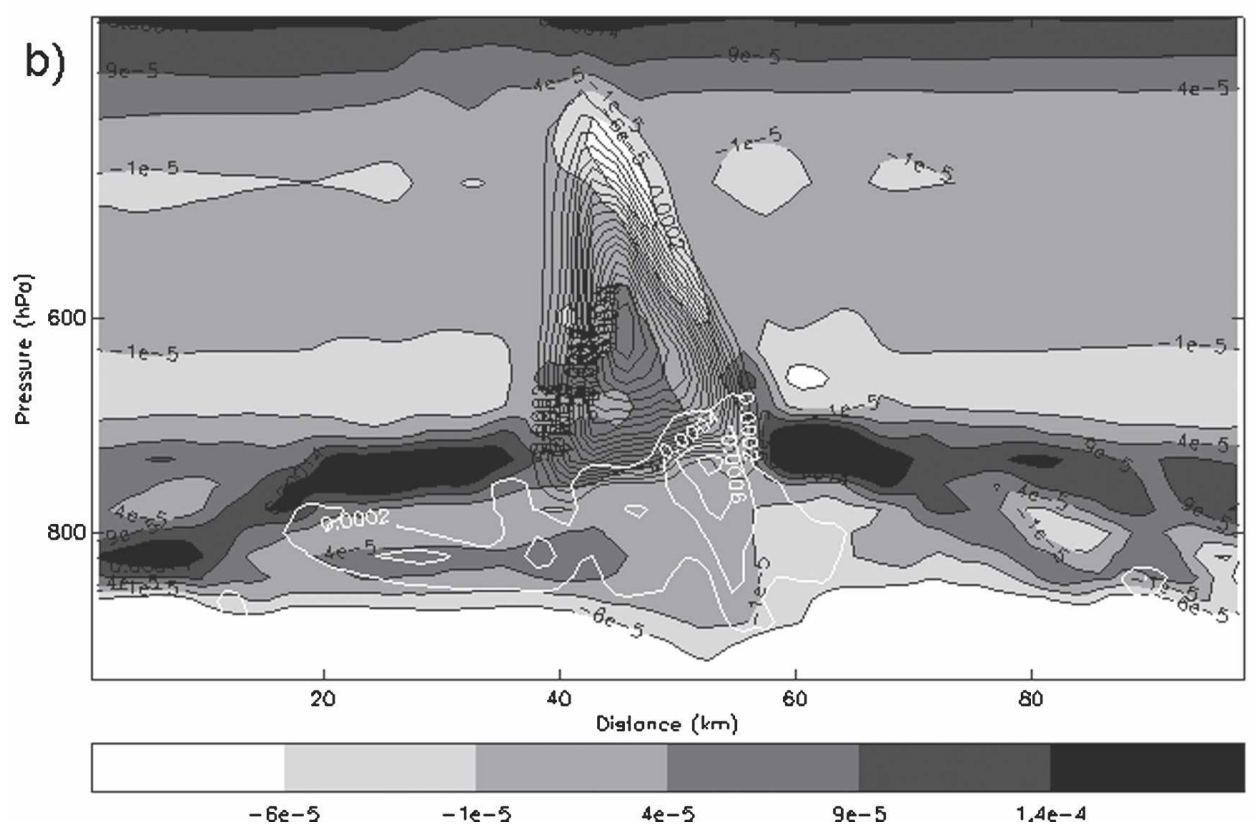

FIG. 15. Vertical cross sections across the convergence line and through the model's main storm showing static stability (shading, $\mathrm{s}^{-2}$ ) and liquid and ice water contents (white and black contours respectively at intervals of $0.2 \mathrm{~g} \mathrm{~kg}^{-1}$ ) at (a) 1100 and (b) $1200 \mathrm{UTC}$, before and after the convection has penetrated the lid.

the $1.5-\mathrm{km}$ model shortly before (Fig. 15a) and after (Fig. 15b) the convection penetrated through the lid. At 1100 UTC (Fig. 15a), the lid had been raised, but it was still capping the convection and only liquid water was present in the cloud. By 1200 UTC (Fig. 15b), the convection had broken through the lid and risen to the height of the tropopause fold, allowing ice to form in the cloud. Meanwhile the other, lighter showers upstream (to the southwest) were still being capped by the lid and had not gone through the transition from shallow to deep convection. The reasons for one cluster of showers deepening and not the others will now be discussed. 


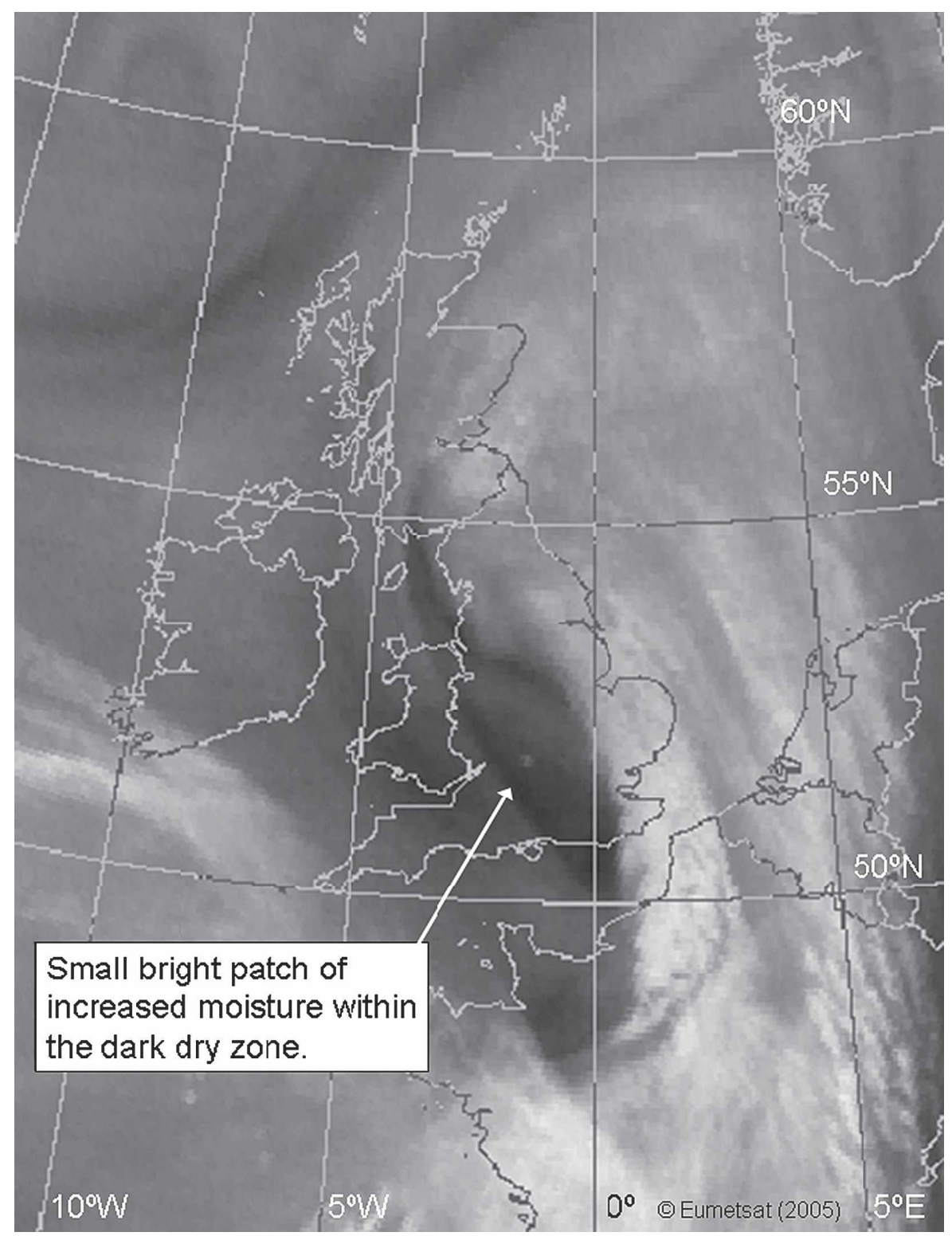

FIG. 16. Meteosat Rapid Scan Water Vapor imagery at 1200 UTC.

\section{Influence of the upper-tropospheric PV anomaly}

\section{a. Nature of the PV anomaly}

The hypothesis to be tested is that the penetration of the lid and extension of the convection from 3 to $7 \mathrm{~km}$ occurred within the convergence line, but only where it was modulated by forcing from an upper-level feature. This occurred in the form of a trough oriented approximately northwest to southeast in association with a traveling upper-level potential vorticity (PV) maximum. Figure 16 shows water vapor imagery for 1200 UTC. There is a dark zone representing relatively dry air located over the United Kingdom at this time. Dark zones in the water vapor imagery are known to be associated with PV maxima, such as occur due to a tropopause depression (Browning 1997). The storm of interest appears as a small bright patch of increased moisture less than $10 \mathrm{~km}$ across embedded within the dark zone. For comparison, Fig. 17a shows the height of the $\mathrm{PV}=2$ surface at $1100 \mathrm{UTC}$ from the $12-\mathrm{km}$ version of the Unified Model.

The height of the PV $=2$ surface can be taken as being representative of the dynamical tropopause (Hoskins et al. 1985). The dark zone associated with drier air in the water vapor imagery corresponds well 

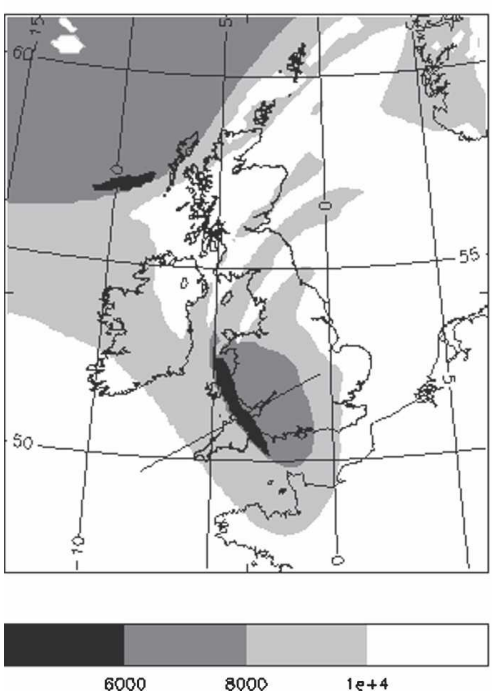

a) b)

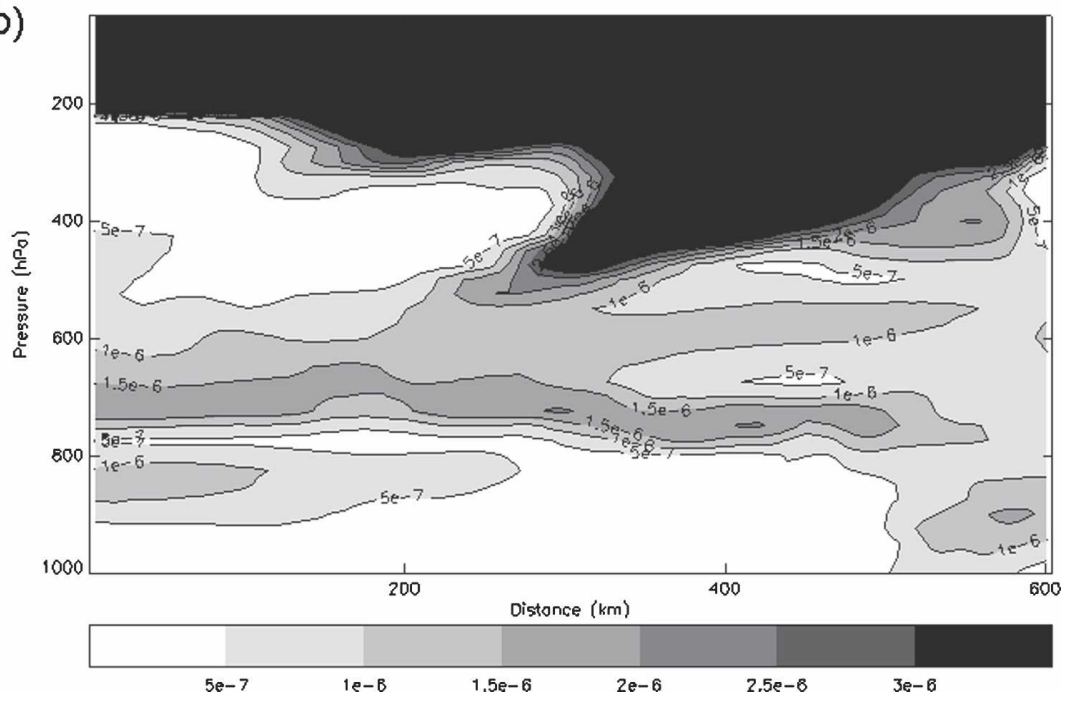

FIG. 17. (a) Geopotential height (m) of the PV $=2$ PVU surface, searching downward, at 1100 UTC from the 12-km model. (b) Vertical cross section of PV at 1100 UTC, taken from SW to NE along the line marked in (a), showing a fold in PV. The lower feature of high PV (between 700-750 hPa) corresponds to the temperature inversion (lid) shown in Fig. 8.

with the PV maximum in the model. This maximum can be tracked back over $24 \mathrm{~h}$ to a PV anomaly (cutoff low) that separated from a larger PV filament extending over the Atlantic south from the Labrador Sea. This large filament preexisted for an additional day over northeastern Canada.

Figure $17 \mathrm{~b}$ is a vertical section oriented as shown in Fig. 17a. It shows the upper-level PV maximum, which was responsible for the trough and the main upper-level forcing, to be associated with a distinct tropopause fold. Beneath it is a shallow layer of high PV corresponding to the lid that was tending to suppress the convection. The PV of this layer was between 1.5 and 2 PV units and it probably originated within, or close to another, different tropopause-fold region. This has been examined in more detail by Russell et al. (2007).

Because the lid is the key feature for controlling the transition from shallow to deep convection, it is of interest to examine how it was formed. Some back trajectories, calculated from ECMWF model data archived on a $1.25^{\circ}$ grid, are used to clarify the origins of the dry tropospheric streamer between 750 and 550 $\mathrm{hPa}$, the bottom edge of which was acting as the lid (Fig. 8). A series of back trajectories initialized from Larkhill $\left(51.2^{\circ} \mathrm{N}, 1.8^{\circ} \mathrm{W}\right)$ at $1200 \mathrm{UTC}$ and starting at 50-hPa intervals between 900 and $200 \mathrm{hPa}$, were calculated from the ECMWF winds. Figure 18 shows a selection of these trajectories and illustrates the origins of the air making up different layers in the thermodynamic profile shown in Fig. 8. These layers (and the pressure at 1200 UTC 15 June) are (i) the boundary layer $(900 \mathrm{hPa})$, (ii) the air just below the lid $(800 \mathrm{hPa})$, (iii) the air just above the lid $(700 \mathrm{hPa})$, and (iv) the middle troposphere $(550 \mathrm{hPa})$.

Figure 18 shows that the air making up the boundary layer ascended gradually and advected from over the Atlantic Ocean, where it will have remained relatively moist. The midtropospheric air initially descended slightly, from 500 to $550 \mathrm{hPa}$. The air that ended up just above the lid descended from above 500 to $700 \mathrm{hPa}$, while the air just below the lid stayed at around 800 $\mathrm{hPa}$. The potential temperature along these latter two trajectories was fairly constant over the preceding 3 days, $29 \pm 1^{\circ} \mathrm{C}$ and $22 \pm 1^{\circ} \mathrm{C}$, respectively, suggesting dry-adiabatic flow. It is the differential vertical motion along these isentropes that led to the formation of the lid at around $750 \mathrm{hPa}$. The formation of the lid by adiabatic descent from midlevels explains the relative dryness of the capping inversion seen in the radiosonde profile. The synoptic-scale ascent of the air on either side of the lid by around $30 \mathrm{hPa}$ over the most recent 8-h period contributed to a weakening of the lid and this, together with the mesoscale lifting along the axis of the boundary layer convergence line (downwind of Devon), enabled the boundary layer convection eventually to break through.

\section{b. Structure of the troposphere accompanying the $P V$ anomaly}

To quantify the synoptic-scale changes in tropospheric structure associated with the passage of the PV anomaly, we have used data from six radiosondes 

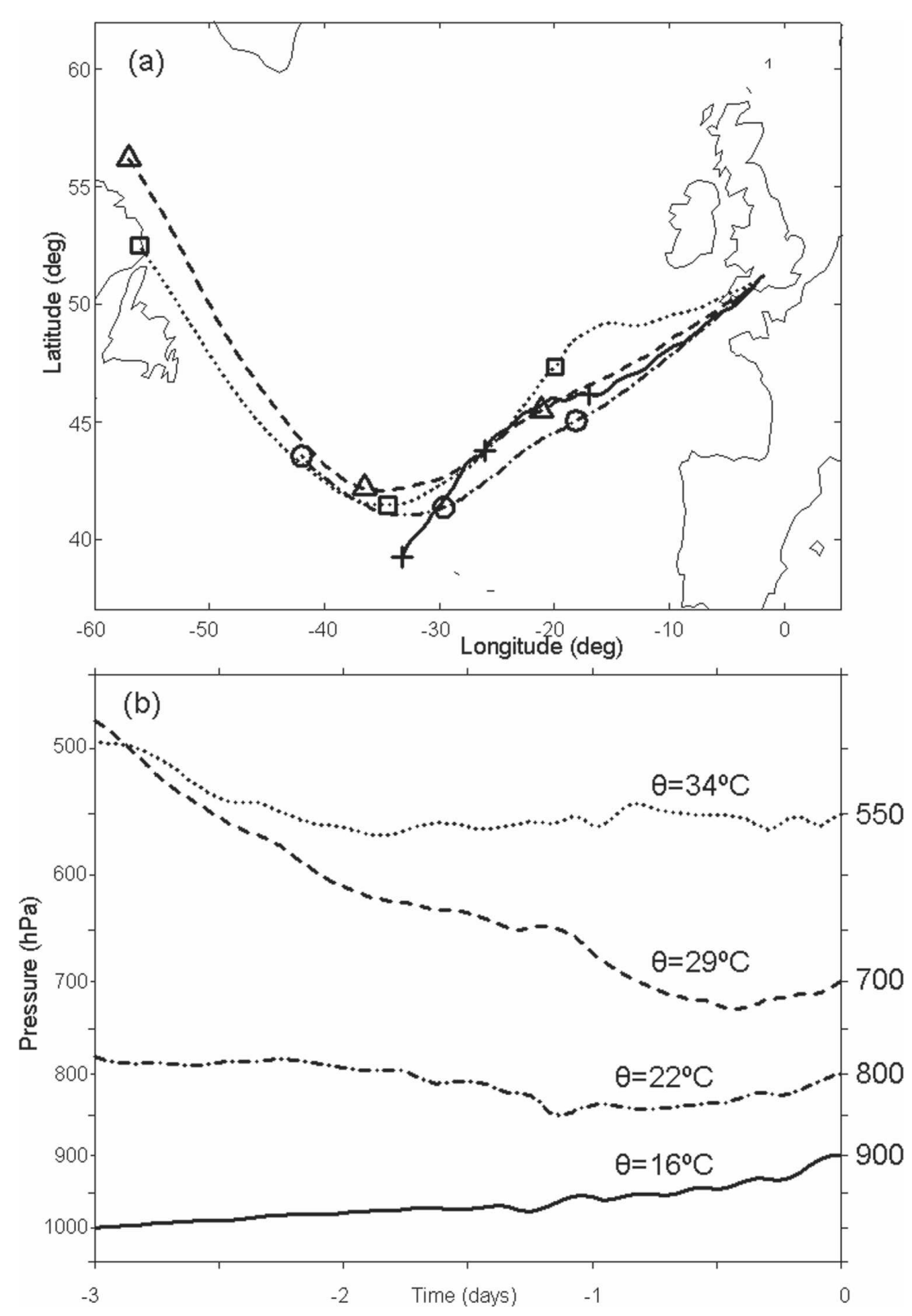

FIG. 18. Three-day back trajectories showing the origin of the air column that was over Larkhill at 1200 UTC 15 Jun 2005. The trajectories are calculated from the ECMWF model (archived on a $1.25^{\circ}$ grid). (a) Map of location of back trajectories and (b) evolution of pressure with time. Line style and symbols distinguishes trajectories in terms of their pressure at 1200 UTC 15 Jun: $900 \mathrm{hPa}$ (solid line and crosses), $800 \mathrm{hPa}$ (dash-dot and circles), $700 \mathrm{hPa}$ (dashed and triangles), and $550 \mathrm{hPa}$ (dotted and squares). Symbols are plotted every $24 \mathrm{~h}$ in (a), and representative values of potential temperature along each trajectory are shown in (b).

launched from Larkhill. The location of Larkhill is indicated in Fig. 2 and the radiosondes were launched at 0540, 0815, 1000, 1200, 1400, and 1600 UTC. Figure 19a shows a time-pressure cross section of the radiosonde data. Because the system was moving eastward, the time axis has been reversed to create a pseudo-west- east cross section. The solid white line near the surface shows the height of the lifting condensation level (LCL). The color shading depicts wet-bulb potential temperature $\theta_{w}$ below the LCL and saturated wet-bulb potential temperature $\theta_{s}$ above it. The saturated wetbulb potential temperature is defined as the wet-bulb 

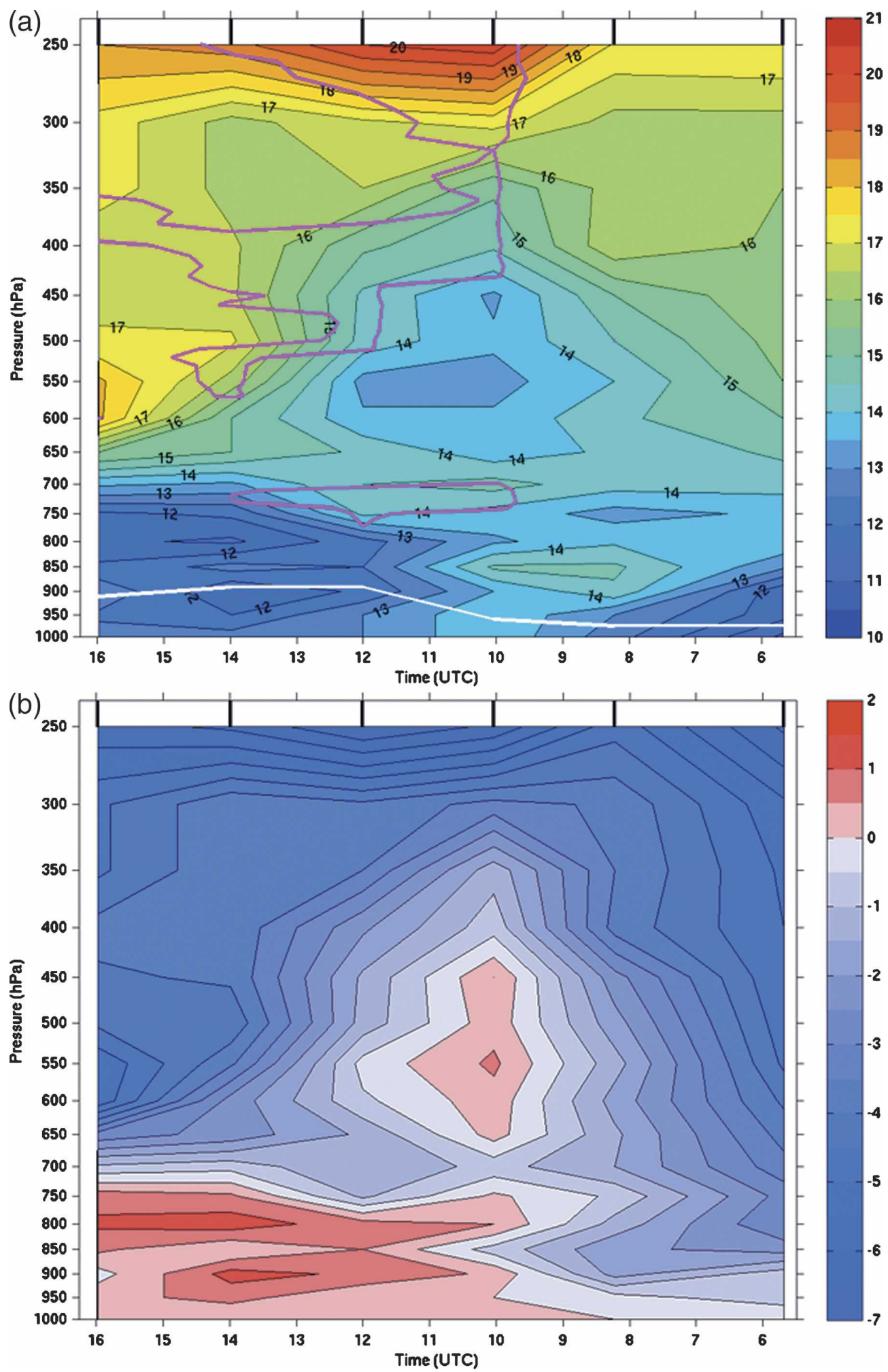

FIG. 19. (a) Time-pressure cross section of $\theta_{s}$ and $\theta_{w}$ constructed from Larkhill radiosonde data. The solid white line indicates the lifting condensation level (LCL); $\theta_{w}$ is plotted below the LCL and $\theta_{s}$ above it $\left({ }^{\circ} \mathrm{C}\right)$. The magenta line is the $10 \%$ relative humidity contour. The time axis is reversed to ease comparison with Fig. 20b. (b) Similar to (a) but showing the value of $\theta_{w}$ or $\theta_{s}$ at all places within the cross section taken away from the surface value of $\theta_{w}\left({ }^{\circ} \mathrm{C}\right)$. The vertical black lines at the top of each panel indicate the launch times of the six radiosondes used to construct the figures. 
potential temperature that the air would have if it were saturated. When comparing parcel and environmental potential temperatures to assess buoyancy, it is necessary to compare the parcel's $\theta_{w}$ to the environment's $\theta_{s}$. The magenta line is the $10 \%$ relative humidity contour.

In the upper troposphere Fig. 19a shows high values of $\theta_{s}$, advected down from the stratosphere, and constituting the tropopause fold, the base of which is seen descending as low as $600 \mathrm{hPa}$ between 1400 and 1600 UTC. A positive PV anomaly, resulting from a tropopause depression associated with a tropopause fold, normally has a cold anomaly located below it (Bishop and Thorpe 1994). Such a cold anomaly is seen in Fig. 19a from 0800 to 1300 UTC between 400 and $650 \mathrm{hPa}$. Between 0930 and $1100 \mathrm{UTC}$, the surface $\theta_{w}\left(13.9^{\circ} \mathrm{C}\right.$ at $1000 \mathrm{UTC})$ is greater than the $\theta_{s}$ of the cold anomaly $\left(13.6^{\circ} \mathrm{C}\right.$ at $\left.550 \mathrm{hPa}\right)$, indicating the potential for deep convection. This convection could not develop at Larkhill however, due to the presence of two lids. The lower lid, centered at $850 \mathrm{hPa}$, was associated with the frontal zone. The main lid, as referred to elsewhere in this paper, was centered at $700 \mathrm{hPa}$. With its low values of relative humidity, air in this lid had descended from the midtroposphere, as discussed in the previous section. It becomes the primary barrier to deep convection after 1000 UTC. The observations shown in Fig. 19a indicate that the $\theta_{s}$ of this lid exceeded the $\theta_{w}$ everywhere in the boundary layer at all times after 1000 UTC. This is as expected because the deep convection did not pass directly over Larkhill; nevertheless, the very presence of the deep convection discussed earlier proves that the lid was penetrated over a limited area nearby.

The importance of the lid at $700 \mathrm{hPa}$ after 1000 UTC is revealed even more clearly in Fig. 19b. The information in Fig. 19b corresponds to that in Fig. 19a, but we have plotted instead the surface value of $\theta_{w}$ minus $\theta_{w}$ or $\theta_{s}$ aloft to give a more direct indication of parcel buoyancy with respect to a parcel originating from the surface. Positive values correspond to regions of positive area on a tephigram (and vice versa). Notice the significant convective inhibition at $700 \mathrm{hPa}$ after 1000 UTC in contrast with the dwindling convective inhibition associated with the lid at $850 \mathrm{hPa}$.

We have made use of data from the $1.5-\mathrm{km}$ model to investigate the key features of the synoptic situation leading to the spatial variability of the instability and the lids. It was found that the structure conformed to the split-front model of Browning and Monk (1982) in which an upper cold front (UCF) overruns a tongue of unoccluded warm-sector air at low levels (i.e., the operational analysis in Fig. 1, depicting an occlusion, is not strictly correct; but, it is common for forecasters, when concerned with the synoptic scales, to analyze split fronts as occlusions for simplicity). Our analysis of a split front is consistent with the radiosonde data from Larkhill (Fig. 19). The $\theta_{s}$ of the lid was a maximum along and behind the axis of the warm tongue, and $\theta_{s}$ in the 600-500-hPa layer was a minimum above the warm tongue, due to the presence of the cold anomaly associated with the upper-level positive PV anomaly. The combination of high surface $\theta_{w}$ and low $\theta_{s}$ at midlevels led to a maximum in potential instability behind the UCF while the high $\theta_{s}$ of the lid compared to the $\theta_{w}$ at the surface is evidence of the capping inversion. Figure 20 summarizes the location of these key features at 1000 UTC just prior to the deepening of the convection. A small surface warm pool $\left(\theta_{w}>14^{\circ} \mathrm{C}\right)$ is located within a narrow south-north low-level warm tongue (Fig. 20a). This warm pool was around $40 \mathrm{~km}$ wide. It corresponds to the shallow moist zone (SMZ) of the split-front model, ahead of a surface cold front (not explicitly marked in Fig. 20a), but behind the UCF. The convergence line, which formed near the coast, can be seen in Fig. 20a to have extended inland into the region of the surface warm pool.

The vertical cross section in Fig. 20b shows the cooler air $\left(\theta_{w}<13^{\circ} \mathrm{C}\right)$ advecting over the surface warm tongue (i.e., SMZ). The overrunning cold air was important because it produced the region of potential instability. Layers of high static stability, or lids, are indicated in Fig. 20b by dashed lines, the thickness of which represents the strength of the lid. One of these lids was associated with the frontal zone. The other lid marked the base of the previously descended dry intrusion. Crucially, the lid was relatively weak over the surface warm pool, because the strongest descent had occurred farther upstream and the air was beginning to ascend again (see Fig. 18b, showing the reascent of the air near the lid over the most recent 8 -h period). This meant that a further small elevation of the lid, resulting from a local forcing mechanism such as the convergence line discussed earlier, was enough to allow convection to penetrate it. This lifting was concentrated along a line oriented southwest to northeast whereas the region of a weaker lid resulting from synoptic-scale ascent behind the upper cold front was oriented northwest to southeast. The thunderstorm developed at the intersection of these two lines.

\section{Summary and conclusions}

A series of shallow light rain showers formed in a region of the deepened boundary layer due to a topographically forced convergence line forming downwind 

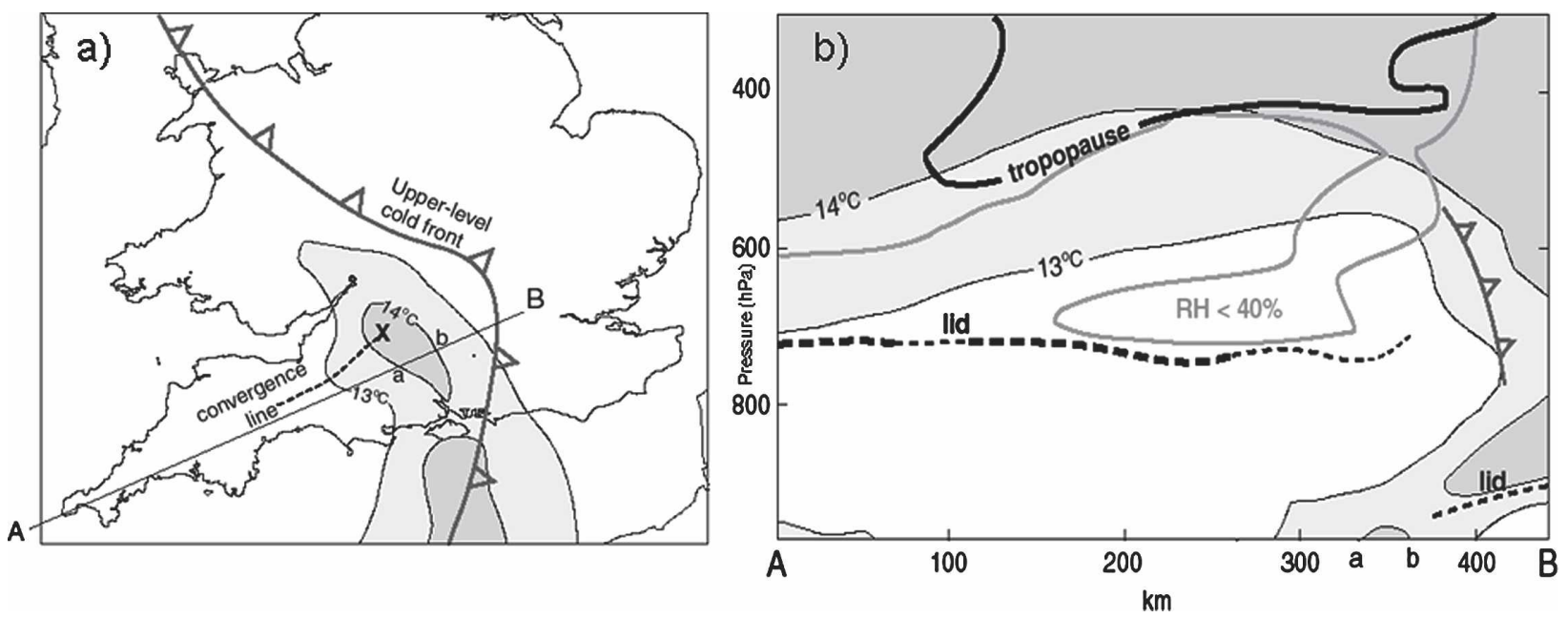

FIG. 20. Summary of the synoptic conditions at 1000 UTC, just prior to the deepening of the convective shower: (a) Analysis of the relative locations of the convergence line, surface warm tongue, and upper-level cold front in the $1.5-\mathrm{km}$ model. The location of the convergence line is shown by the dashed line. The position of the upper-level cold front is based on the $\theta_{w}=13^{\circ} \mathrm{C}$ isentrope at $750 \mathrm{hPa}$. The line A-B shows the orientation of the cross section in (b). (b) Vertical cross section along the line A-B shown in (a). In both panels, the shading indicates wet-bulb potential temperature: $\theta_{w}<13^{\circ} \mathrm{C}$ (white), $13^{\circ} \mathrm{C}<\theta_{w}<14^{\circ} \mathrm{C}$ (light gray), $\theta_{w}>14^{\circ} \mathrm{C}($ dark gray) and the lowercase letters "a" and "b" highlight the location of a shallow pool of warm air. The strong horizontal temperature gradient at the leading edge of the overriding low- $\theta_{w}$ air has been analyzed as the upper cold front. The dry region, with relative humidity less than $40 \%$, is shown in (b) by the bold gray line. The tropopause has been drawn in (b) along the PV $=2$ contour. Two regions of high static stability at low levels have been identified as lids. The thickness of the dashed lines represents the strength of the lid. One of these is associated with the warm-sector air lagging behind the upper cold front. The other, at about $700 \mathrm{hPa}$, corresponds to the main lid as analyzed in this paper.

of Devon in the southwest of the United Kingdom. The convection from the surface was capped by a lid formed by a streamer of previously subsided relatively warmer air. One of these showers developed into a small cluster of deep convective showers with heavy rain rates and some thunder. The shower that broke through the lid did so in an area where the lid was weaker. There was no other development of deep convection along the convergence line because farther northeast, the frontal zone prevented convective development while farther southwest the lid was stronger. The instability experienced by the deep convection was augmented by the presence of a cold anomaly at midlevels associated with an upper-level PV anomaly. The location where the lid broke occurred where two key features intersected: the region of a weaker lid resulting from the dynamically forced ascent in the vicinity of, and just behind, the upper cold front (oriented approximately northwest to southeast); and the region of lifting resulting from the topographically forced convergence line (oriented approximately southwest to northeast).

This study has shown that the $1.5-\mathrm{km}$ model is capable of representing the evolution of the mesoscale structure of the atmosphere associated with the transition from shallow to deep convection. The model successfully forecast the synoptic conditions, including the presence of an upper-level positive PV anomaly and associated midlevel cold anomaly. The presence of a tongue of warm $\theta_{w}$ air near the surface led to instability and the potential for deep convection. The model correctly represented the presence of a capping inversion, or lid, and its modulation by a convergence line. As a result of the model successfully representing the interaction between the convergence line, the lid, and the cold anomaly, it was able to pinpoint the transition from shallow convective showers to a deep thunderstorm.

In this case, the success of the model depended on accurate representation of two scales: the synoptic (which was well forecast by the coarser-resolution models driving the $1.5-\mathrm{km}$ model) and the surface-forced mesoscale convergence line, which was well resolved by the model and appears to be quite predictable. The precise mechanism for the formation of this convergence line will be the subject of a subsequent paper. The interaction between the two scales localized the convection sufficiently in space and time for the initiation and subsequent development to be highly predictable, in spite of the relatively poor representation of processes at the cloud scale. This is a good example of nonequilibrium convection, as discussed by Done et al. (2006), and its association with a high level of predict- 
ability once the surface-forced flows are properly resolved. The details of the shower, and the later stages of development of the shower cluster, were more dependent on small-scale processes and less well simulated.

It follows that to improve the forecast via assimilation of observations would require improvement of the synoptic scale, via the large-scale data assimilation system, and/or improved location of the convergence line before precipitation forms. The latter points to the potential importance of clear-air Doppler radar data, lowlevel 2D moisture data (e.g., Fabry et al. 1997), and the full use of satellite imagery of the early stages of cloud development.

Acknowledgments. Thanks are due to the Natural Environment Research Council and the Met Office National Meteorology Programme for funding CSIP. We wish to thank everyone who participated in the CSIP observational campaign: Judith Agnew, Dave Bamber, Lindsay Bennett, Barbara Brooks, Ulrich Corsmeier, Norbert Kalthoff, Sarah Keeley, Darcy Ladd, James McGregor, Emily Norton, Felicity Perry, and Markus Ramatschi. Thanks are due to Brian Golding and three anonymous reviewers for their comments on earlier versions of this paper. Thanks are due to the Met Office for the radar network rain-rate data and for launching extra radiosondes from Larkhill. Thanks are also due to Eumetsat for the Meteosat- 8 high-resolution visible and water vapor channel data and to the British Atmospheric Data Centre (BADC) for archiving the data collected during CSIP. The project exploited new instruments available through the Universities' Facility for Atmospheric Measurement (UFAM), which is funded by the Natural Environment Research Council following an initial award from the HEFCE Joint Infrastructure Fund. The Chilbolton Observatory, around which the project is based, is managed by John Goddard and owned by the Council for the Central Laboratory of the Research Councils.

\section{REFERENCES}

Bader, M. J., G. S. Forbes, J. R. Grant, R. B. E. Lilley, and A. J. Waters, 1995: Images in Weather Forecasting: A Practical Guide for Interpreting Satellite and Radar Imagery. Cambridge University Press, 499 pp.

Barnes, S. L., 1964: A technique for maximizing details in numerical weather map analysis. J. Appl. Meteor., 3, 396-409.

Bennett, L. J., K. A. Browning, A. M. Blyth, D. J. Parker, and P. A. Clark, 2006: A review of the initiation of convection in the United Kingdom. Quart. J. Roy. Meteor. Soc., 132, 10011020.

Bishop, C. H., and A. J. Thorpe, 1994: Potential vorticity and the electrostatic analogy: Quasi-geostrophic theory. Quart. J. Roy. Meteor. Soc., 120, 713-731.
Browning, K. A., 1997: The dry intrusion perspective of extratropical cyclone development. Meteor. Appl., 4, 317-324.

— analysis of cold fronts. Quart. J. Roy. Meteor. Soc., 108, 435452.

- and Coauthors, 2006: A summary of the Convective Storm Initiation Project Intensive Observation Periods. Met Office, Joint Centre for Mesoscale Meteorology Rep. 153, 164 pp.

Burt, S., 2005: Cloudburst upon Hendraburnick Down: The Boscastle storm of 16 August 2004. Weather, 60, 219-227.

Clark, P. A., and H. W. Lean, 2006: An overview of high resolution UM performance for CSIP cases. Met Office, Joint Centre for Mesoscale Meteorology Rep. 155, 44 pp.

Collier, C. G., 1996: Applications of Weather Radar Systems. 2d ed. John Wiley and Sons with Praxis Publishing, 390 pp.

Cullen, M. J. P., 1993: The unified forecast/climate model. Meteor. Mag., 122, 81-94.

Davies, T., M. J. P. Cullen, A. J. Malcolm, M. H. Mawson, A. Staniforth, A. A. White, and N. Wood, 2005: A new dynamical core for the Met Office's global and regional modelling of the atmosphere. Quart. J. Roy. Meteor. Soc., 131, 1759-1782.

Done, J. M., G. C. Craig, S. L. Gray, P. A. Clark, and M. E. B. Gray, 2006: Mesoscale simulations of organised convection: Importance of convective-equilibrium. Quart. J. Roy. Meteor. Soc., 132, 737-756.

Fabry, F., C. Frush, I. Zawadzki, and A. Kilambi, 1997: Extracting near-surface index of refraction using radar phase measurements from ground targets. J. Atmos. Oceanic Technol., 14, 978-987.

Goddard, J. W. F., J. D. Eastment, and M. Thurai, 1994: The Chilbolton Advanced Meteorological Radar: A tool for multidisciplinary atmospheric research. Electron. Commun. Eng. J., 6, 77-86.

Golding, B., 1998: Nimrod: A system for generating automated very short range forecasts. Meteor. Appl., 5, 1-16.

- 2005: A new approach to nowcasting at the Met Office. Extended Abstracts, World Weather Research Program Symp. on Nowcasting and Very-Short Range Forecasting, Toulouse, France, WMO, 7.35, 1-9.

_ P. Clark, and B. May, 2005: Boscastle flood: Meteorological analysis of the conditions leading to flooding on 16 August 2004. Weather, 60, 230-235.

Gossard, E. E., and R. G. Strauch, 1983: Radar Observations of Clear Air and Clouds. Elsevier, 280 pp.

— D. E. Wolfe, K. P. Moran, R. A. Paulus, K. D. Anderson, and L. T. Rogers, 1998: Measurement of clear-air gradients and turbulence properties with radar wind profilers. $J$. Atmos. Oceanic Technol., 15, 321-342.

Gregory, D., and P. R. Rowntree, 1990: A mass flux convection scheme with representation of cloud ensemble characteristics and stability-dependent closure. Mon. Wea. Rev., 118, 14831506.

Hoskins, B. J., M. E. McIntyre, and A. W. Robertson, 1985: On the use and significance of isentropic potential vorticity maps. Quart. J. Roy. Meteor. Soc., 111, 877-946.

Hunt, J. C. R., A. Orr, J. W. Rottman, and R. Capon, 2004: Coriolis effects in mesoscale flows with sharp changes in surface conditions. Quart. J. Roy. Meteor. Soc., 130, 2703-2731.

Lee, A. C. L., 1990: Bias elimination and scatter in lightning location by the VLF arrival time difference technique. J. Atmos. Oceanic Technol., 7, 719-733.

Marshall, J. S., and W. M. Palmer, 1948: The distribution of raindrops with size. J. Meteor., 5, 165-166. 
Morcrette, C. J., K. A. Browning, A. M. Blyth, K. E. Bozier, P. A. Clark, D. Ladd, E. G. Norton, and E. Pavelin, 2006: Secondary initiation of multiple bands of cumulonimbus over southern Britain. Part I: An observational case study. Quart. J. Roy. Meteor. Soc., 132, 1021-1051.

Orlanski, I., 1975: A rational subdivision of scales for atmospheric processes. Bull. Amer. Meteor. Soc., 56, 527-530.

Russell, A., G. Vaughan, E. Norton, C. Morcrette, K. Browning, and A. Blyth, 2007: Convective inhibition beneath an upperlevel PV anomaly. Quart. J. Roy. Meteor. Soc., in press.

Schmetz, J., P. Pili, S. Tjemkes, D. Just, J. Kerkmann, S. Rota, and A. Ratier, 2002: An introduction to Meteosat Second Generation (MSG). Bull. Amer. Meteor. Soc., 83, 977-992.

Simpson, J. E., 1997: Gravity Currents in the Environment and the Laboratory. $2 \mathrm{~d}$ ed. Cambridge University Press, 244 pp.

Starr, J. R., 1997: Forecasters' Reference Book. Met Office, 277 pp. 